Article

\title{
Novel Cellulose Derivatives Containing Metal (Cu, Fe, Ni) Oxide Nanoparticles as Eco-Friendly Corrosion Inhibitors for C-Steel in Acidic Chloride Solutions
}

\author{
Mohamed Gouda ${ }^{1, *}$ and Hany M. Abd El-Lateef $1,2, *$ (D) \\ 1 Chemistry Department, College of Science, King Faisal University, Al-Ahsa 31982, Saudi Arabia \\ 2 Chemistry Department, Faculty of Science, Sohag University, Sohag 82524, Egypt \\ * Correspondence: mgoudaam@kfu.edu.sa (M.G.); hmahmed@kfu.edu.sa or \\ hany_shubra@science.sohag.edu.eg (H.M.A.E.-L.)
}

Citation: Gouda, M.; El-Lateef, H.M.A. Novel Cellulose Derivatives Containing Metal (Cu, Fe, Ni) Oxide Nanoparticles as Eco-Friendly Corrosion Inhibitors for C-Steel in Acidic Chloride Solutions. Molecules 2021, 26, 7006. https://doi.org/ $10.3390 /$ molecules 26227006

Academic Editor: Bogumil E. Brycki

Received: 27 October 2021

Accepted: 18 November 2021

Published: 19 November 2021

Publisher's Note: MDPI stays neutral with regard to jurisdictional claims in published maps and institutional affiliations.

Copyright: (c) 2021 by the authors. Licensee MDPI, Basel, Switzerland. This article is an open access article distributed under the terms and conditions of the Creative Commons Attribution (CC BY) license (https:/ / creativecommons.org/licenses/by/ $4.0 /)$.

\begin{abstract}
Novel environmentally-friendly corrosion inhibitors based on primary aminated modified cellulose (PAC) containing nano-oxide of some metals (MONPs), for instance iron oxide nanoparticles ( $\mathrm{Fe}_{3} \mathrm{O}_{4} \mathrm{NPs}$ ), copper oxide nanoparticles (CuONPs), and nickel oxide nanoparticles (NiONPs), were successfully synthesized. The as-prepared PAC/MONPs nanocomposites were categorized using Fourier transform infrared spectroscopy (FT-IR), transmission electron microscope (TEM), fieldemission scanning electron microscopy (FE-SEM), energy-dispersive X-ray spectroscopy (EDX), $X$-ray diffraction (XRD), and selected area diffraction pattern (SAED) techniques. The data from spectroscopy indicated that successful formation of PAC/MONPs nanocomposites, as well as the TEM images, declared the synthesized PAC/ $\mathrm{Fe}_{3} \mathrm{O}_{4} \mathrm{NPs}$, PAC/CuONPs, and PAC/NiONPs with regular distribution with particle size diameters of 10, 23 and $43 \mathrm{~nm}$, respectively. The protection performance of the as-prepared PAC and PAC/MONPs nanocomposites on the corrosion of C-steel in molar $\mathrm{HCl}$ was studied by the electrochemical and weight-loss approaches. The outcomes confirmed that the protection power increased with a rise in the [inhibitor]. The protection efficiency reached 88.1, 93.2, 96.1 and 98.6\% with 250 ppm of PAC/CuONP, PAC/ $\mathrm{Fe}_{3} \mathrm{O}_{4} \mathrm{NPs}$, and PAC/NiONPs, respectively. PAC and all PAC/MONPs nanocomposites worked as mixed-kind inhibitors and their adsorption on the C-steel interface followed the isotherm Langmuir model. The findings were reinforced by FT-IR, FE-SEM and EDX analyses.
\end{abstract}

Keywords: cellulose derivatives; corrosion inhibitors; metal oxide nanoparticles; cellulose nanocomposites; Electrochemical Impedance Spectroscopy; surface morphology

\section{Introduction}

Corrosion is a dangerous phenomenon devastatingly affecting mechanical and modern applications, especially in the oil and gas enterprises. Consequently, regulatory metal decomposition is a significant action of specialized, affordable, ecological, and appealing significance to spare tremendous costs in resources, hardware, and construction. The utilization of corrosion inhibitors is perhaps the most ideal choice for governing the corrosion of metals in different harsh media. Through the utilization of little particle organic and inorganic corrosion inhibitors for different issues, the utilization of corrosion inhibitors based on polymers came into the spotlight [1]. Polymers are materials that have fantastic adhesive properties on metal surfaces. A wide scope of polymers have been identified for their corrosion resistant properties as both pre-covering [2] on the metal or just as an inhibitor in an assortment of corrosive liquids [3-10]. Furthermore, the use of carbohydrate polymers in corrosion hindrance gave a course to utilize materials that are biodegradable, artificially steady, eco-friendly with the one-of-a-kind repressing property, low cost, and renewable [11,12]. The molecular weights decide the quality of carbohydrate polymers as inhibitors, the nearness of adsorption focuses, accessibility of security shaping 
gatherings, and the nearness of cyclic rings in the class of the carbohydrate [13]. The corrosion restraining exercises of these polymers are ascribed to their capacity to frame edifices with metal particles on the outside of metals through their practical gathering. The complex is framed to cover the outside of the metals because of their enormous surface region, subsequently shielding the metals from destructive species present in their condition [14]. This inhibitive action relies upon the cyclic rings and heteroatoms (nitrogen and oxygen) present in the structure of the polymer. In addition, the possible utilization of carbohydrate polymers has been assessed in an expansive range of fields, for example, medication conveyance [15], adsorption [16], wastewater treatment [17,18], consumption obstruction [19], and catalysis [20]. Cellulose is the amongst the carbohydrate polymers and is sustainable by practically limitless crude material and particularly encouraging as it delivers great mechanical execution with likely biocompatibility, non-harmfulness, biodegradability, and the existence of reactive gatherings. This last element is engaging, as its additional modification would be possibly helpful when used to include another polymer, or adjust their properties which will offer new and capricious applications [21].

Moreover, cellulose is the most bountiful water-insoluble natural polysaccharide. Semi water-insoluble cellulose derivatives are engineered simply of cellulose. The corrosion inhibitor properties of cellulose derivatives were identified for mild steel in various acid solutions [7-9]. Bayol et al. have considered the adsorptive conduct of cellulose derivatives on mild steel in $\mathrm{HCl}$ solution [7]. Umoren et al. revealed the hindrance capability of cellulose derivatives for sulphuric acid corrosion of steel [8,9], and the impacts of synergism and enmity of halide ions with cellulose derivatives on the corrosion restraint. The electrochemical properties of meager films of two subsidiaries of the biopolymer, hydroxypropyl methylcellulose, specifically hydroxypropyl methylcellulose phthalate and hydroxypropyl methylcellulose acetate succinate, in an emphatically acidic condition were examined. The corrosion resistance of hydroxypropyl methylcellulose-subordinate covered steel was assessed utilizing electrochemical impedance spectroscopic estimations and potentiodynamic polarization [22].

It is reported that for organic materials, for example, polymers or macromolecules, having utilitarian gatherings (-OH, $-\mathrm{COOH},-\mathrm{NH}_{2}$, and so on), are seen as anti-corrosive materials in various destructive media [8,9,23-32]. Bigger corrosion hindrance efficiencies that have been observed utilizing polymers are not just because of the nearness of $\pi$-electrons; however, it very well may be likewise ascribed to the bigger sub-atomic size which guarantees more prominent inclusion of metallic surface [30]. Hydroxyethylcellulose is a water-solvent polymer obtained from cellulose, and is a moderately modest, non-harmful, eco-accommodating corrosion inhibitor. It has broad applications as a folio, thickener, stabilizer, suspension, and water-holding specialist in the food business, pharmaceutical, corrective, paper, and other mechanical regions [33]. Hydroxyethylcellulose has been investigated to hinder the corrosion of aluminum and steel in $\mathrm{HCl}$ solutions [34].

With the quick progression of nanotechnology, slight thickness films in the micrometric and nanometric measures are expanding their notoriety in logical and innovative uses [35]. Nanoscale materials have a high propensity to cooperate to frame accumulation [36]. Its one-of-a-kind properties are fundamental because of the greater surface area of the nanoscale compounds in contrast with the micro-scaled compounds brought about by its enormous surface area to volume ratio [37]. There are different reports regarding the enhancement of corrosion resistance utilizing nanoparticles, for instance, $\mathrm{TiO}_{2}$ [38], $\mathrm{Cu}_{2} \mathrm{O}$ [39], $\mathrm{ZnO}$ [40], $\mathrm{ZrO}_{2}$ nanoparticles [41], $\mathrm{Fe}_{3} \mathrm{O}_{4}$ [42], $\mathrm{SiO}_{2}$ [43] and organo-clay nanoparticles [44]. In addition, metal oxide nanoparticles are of unique enthusiasm owing to their differing structure, optical, magnetic, mechanical, thermal, and electronic features. Among the wide assortment of metal oxide nanoparticles, Taiwo et al. prepared and characterized nanocomposites of some designated polymers, namely, poly(vinylpyrrolidone), poly(ethylene glycol), and polyacrylonitrile containing $\mathrm{ZnO}$, and studied their application as inhibitors for the corrosion of C-steel in hydrochloric acid solution [45]. 
Herein, primary aminated modified cellulose (PAC) and $\mathrm{Fe}_{3} \mathrm{O}_{4} \mathrm{NPs}, \mathrm{CuONP}$ and NiONPs in PAC structure were designed and smoothly fabricated by using in situ deposition. The as-prepared materials were characterized via Fourier transform infrared spectroscopy (FT-IR), field-emission scanning electron microscopy (FE-SEM)/energy-dispersive X-ray spectroscopy (EDX), X-ray diffraction (XRD), transmission electron microscope (TEM), and selected area diffraction pattern (SAED). Moreover, we report, for the first time, the application of PAC and $\mathrm{Fe}_{3} \mathrm{O}_{4} \mathrm{NPs}, \mathrm{CuONP}$ and NiONPs in PAC structure, as corrosion inhibitors for $\mathrm{C}$-steel in $\mathrm{HCl}$ solution. Weight loss, electrochemical (PDP and EIS), and surface topology measurements (FT-IR and FE-SEM/EDX), were used to identify the anti-corrosive activity.

\section{Experimental Procedures}

\subsection{Materials}

Microcrystalline cellulose by a degree of polymerization (DP) of 10,000, nickel nitrate, copper chloride, ferric chloride, isopropyl alcohol, $\mathrm{H}_{2} \mathrm{SO}_{4}(98 \%)$, sodium borohydride, 1,2-epoxypropene (98\%) and $\mathrm{NH}_{4} \mathrm{OH}(37 \%)$ were obtained from Sigma-Aldrich Co. (Saint Louis, MO, USA). The primary amine reagent was synthesized according to the reported method [46]. Further chemicals of analytical grade were used without further refinement.

The working electrodes for experiments were made of C-steel (C1018) and have an area of $0.5 \mathrm{~cm}^{2}$ with a chemical structure $(\mathrm{wt} \%)$ of manganese $(0.06 \%)$, carbon $(0.19 \%)$, chromium $(0.75 \%)$, nickel $(0.06 \%)$, and iron $(98.94 \%)$. The mechanical characteristics of the C-steel were measured and provided by the supplier displayed as follows: tensile strength $\approx 490 \mathrm{MPa}$ and elongation to failure $\approx 16 \%$. The findings were provided by European Corrosion Supplies Ltd. The electrode was used without any modifications. The protecting performance of the prepared nanocomposites was measured at six various doses quantified by $25,50,100,150,200$, and $250 \mathrm{mg} \mathrm{L}^{-1}$.

\subsection{Synthesis of Primary Amine (PA)}

Primary amine was synthesized by adding one mole of ammonia to one mole of epichlorohydrine $(\mathrm{ECH})$ in the presence of $100 \mathrm{~mL}$ isopropanol. The mixture was stirred at 31-34 ${ }^{\circ} \mathrm{C}$ for $7 \mathrm{~h}$. At the end of the reaction, the excess of isopropanol was removed by a rotary evaporator at $30^{\circ} \mathrm{C}$ under vacuum. Unreacted $\mathrm{ECH}$ was removed by five frequent washes with chloroform.

\subsection{Synthesis of Cellulose Containing Primary Amino Group (PAC)}

PAC was synthesized according to the reported procedure [47] as follows: 1.0 mole of microcrystalline cellulose was continuously mechanical stirred at $25^{\circ} \mathrm{C}$ for $5 \mathrm{~min}$ in the presence of 1.0 mole of sodium hydroxide. Synthesized primary amine reagent (3-chloro2-hydroxypropyl amine) was added to the aforementioned mixture under continuous stirring for $5 \mathrm{~min}$ at $25{ }^{\circ} \mathrm{C}$. The mixture was transferred to the thermostatic water at $80^{\circ} \mathrm{C}$ for $180 \mathrm{~min}$. At the end of the reaction duration, the synthesized samples were acidified with $1.0 \mathrm{~N} \mathrm{HCl}$ solution. The prepared acidified samples were washed with an ethanol/water mixture (80:20) for $12 \mathrm{~h}$ at $70^{\circ} \mathrm{C}$ to remove unreacted amine using a soxhlet extractor. The degree of substitution (DS) of synthesized PAC was investigated based on a measure of their nitrogen content using the Kjeldahl procedure. DS of synthesized PAC was 0.33 .

\subsection{Synthesis of PAC/MONPs Nanocomposites}

PAC containing MONPs was synthesized according to the reported route [48]. To a weighing bottle containing $100 \mathrm{~mL}$ of $0.5 \mathrm{M}$ metal salt solution (isopropyl alcohol/water $50: 50)(v / v \%) 0.5 \mathrm{~g}$ PAC was added. The $\mathrm{pH}$ of the reaction mixture was adjusted to $\mathrm{pH} 9.5$ and kept shaken at $25^{\circ} \mathrm{C}$ for $24 \mathrm{~h}$. At the end of the duration time, sodium borohydride $(0.25 \mathrm{~g})$ was added. The aforementioned reaction mixture was transferred to the ultrasonic sonication bath for $30 \mathrm{~min}$ with constant stirring using a mechanical stirrer for $30 \mathrm{~min}$ at 
$25{ }^{\circ} \mathrm{C}$. The prepared samples were filtered-off, washed and dried at $80^{\circ} \mathrm{C}$ for $2 \mathrm{~h}$. The dried samples were transferred to the furnace at $400{ }^{\circ} \mathrm{C}$ for $8 \mathrm{~h}$.

\subsection{Physicochemical Characterization}

Surface morphology of primary aminated cellulose without and with metal oxide nanoparticles was portrayed using FE-SEM supplemented with EDX (JOELF, Tokyo, Japan). Diameter and distribution, as well as the diffraction of prepared nanocomposites, were investigated by transmission electron microscopy (TEM) coupled with SAED (TEM-ZEISSEM-10-GERMANY). The crystal pattern of the primary aminated cellulose without and with metal oxide nanoparticles was assessed utilizing X-ray diffraction with a $2 \theta$ extended from $10^{\circ}$ to $80^{\circ}$ (Rigaku, Tokyo, Japan). Furthermore, primary aminated cellulose without and with metal oxide nanoparticles was characterized utilizing FTIR spectrometer-8400S (SHIMADZU, Kyoto, Japan) to the range of $400-4000 \mathrm{~cm}^{-1}$.

\subsection{Corrosion Measurements and Experimental Setup}

The corrosion experiments were performed at atmospheric pressure using an orthodox three-electrode system. The C-steel with an immersed surface area of $1.0 \mathrm{~cm}^{2}$ functioned as a working electrode, a Pt-mesh electrode as a counter, and a silver/silver chloride/ $\mathrm{KCl}_{\text {sat }}$ electrode as a reference. The protective action of the nanocomposite additives on the corrosion of C-steel in hydrochloric acid medium was examined by the Gamry Galvanostat/Potentiostat/ZRA analyzer. Prior to each experiment, a steady open circuit potential $\left(E_{\mathrm{OCP}}\right)$ was reached within $40 \mathrm{~min}$ after the specimen was dipped in the corrosive medium. EIS tests were carried out within the frequency range of $0.3 \mathrm{MHz}$ to $100 \mathrm{kHz}$ at the $E_{\mathrm{OCP}}$. Furthermore, PDP studies were achieved in the potential range of $\pm 250 \mathrm{mV}$ vs. $E_{\mathrm{OCP}}$ at a scan rate of $0.2 \mathrm{mV} / \mathrm{s}$. Slope lines at the overpotentials of cathodic and anodic branches of Tafel diagrams were induced by Gamry Echem Analyst software version $5.50[4,5]$. All corrosion experiments were repeated three-times to ensure the accurateness of the experimental outcomes. The weight loss procedures were similarly performed as titled in our earlier study [3]. The corrosion tests were completed at a temperature range from 303 to $333 \mathrm{~K}$.

\subsection{Surface Topology Investigations}

The surface investigation by FE-SEM/EDX (JOELF, Tokyo, Japan) of the working electrode was attained after exposure to these specimens for $48 \mathrm{~h}$ in molar hydrochloric acid in the absence and existence of $250 \mathrm{mg} / \mathrm{L}$ of PAC and PAC/NiO NPs at $303 \mathrm{~K}$. Additionally, the protecting layer designed at the $\mathrm{C}$-steel $/ \mathrm{HCl}$ interface containing $\mathrm{PAC} / \mathrm{NiO}$ NPs inhibitor were inspected by accumulating the formed film after $48 \mathrm{~h}$ of dipping by scrabbling the C-steel substrates, washing them with bidistilled $\mathrm{H}_{2} \mathrm{O}$, and then testing them through an FT-IR instrument.

\section{Results and Discussion}

3.1. Characterizations of PAC/MONPs Nanocomposites

\subsubsection{FTIR}

FT-IR investigation of cellulose, $\mathrm{PAC}, \mathrm{PAC} / \mathrm{NiONPs}, \mathrm{PAC} / \mathrm{CuONPs}$ and $\mathrm{PAC} / \mathrm{Fe}_{3} \mathrm{O}_{4} \mathrm{NPs}$ are shown in Figure 1. The bands are found in two wavenumber regions of 3681-2801 $\mathrm{cm}^{-1}$ and 1651-405 $\mathrm{cm}^{-1}$, which represent the unmodified cellulose. The distinctive beaks at $3501-3001,2895,1429,1028$, and $893 \mathrm{~cm}^{-1}$ are conforming to the vibration of $-\mathrm{OH},-\mathrm{C}-\mathrm{H}-$, $-\mathrm{CH}_{2}$ bending, -C-O-C- of pyranose ring, and the $\beta(1 \rightarrow 4)$-unhydroglycosidic link, correspondingly [49]. With regard to PAC, the results showed that it is similar to unmodified cellulose, as the results showed the presence of the $\mathrm{OH}$ stretching with an increase in the bandwidth, which designates the presence of the $-\mathrm{N}-\mathrm{H}$. In addition, a weak band was observed with very small intensity at $1301 \mathrm{~cm}^{-1}$, which designates the occurrence of expansion vibrations of the $\mathrm{C}-\mathrm{N}$ bond, confirming the presence of an amino substitute in cellulose [50]. Moreover, Figure 1 shows FTIR spectra PAC/MONPs, and the obtained spec- 
tra revealed that the band that concerned $\mathrm{OH}$ converts to low intensity in PAC/NiONPs and disappeared in PAC/CuONPs and PAC $/ \mathrm{Fe}_{3} \mathrm{O}_{4} \mathrm{NPs}$. Alternatively, in PAC/NiONPs, PAC/CuONPs, and PAC $/ \mathrm{Fe}_{3} \mathrm{O}_{4} \mathrm{NPs}$, the $\mathrm{C}-\mathrm{N}$ peak appeared as a weak band with low intensity at 1345,1375 , and $1363 \mathrm{~cm}^{-1}$, correspondingly. Furthermore, the band regarding the pyranose ring -C-O-C- became weak and shifted in all FAC/MONPs. Additionally, weak representative bands at 457,481 , and $535 \mathrm{~cm}^{-1}$ are allocated to PAC/NiONPs, $\mathrm{PAC} / \mathrm{CuONPs}$, and $\mathrm{PAC} / \mathrm{Fe}_{3} \mathrm{O}_{4} \mathrm{NPs}$ vibration, respectively. These results proved the formation of nMO/Acell nanocomposites successfully [51-53].

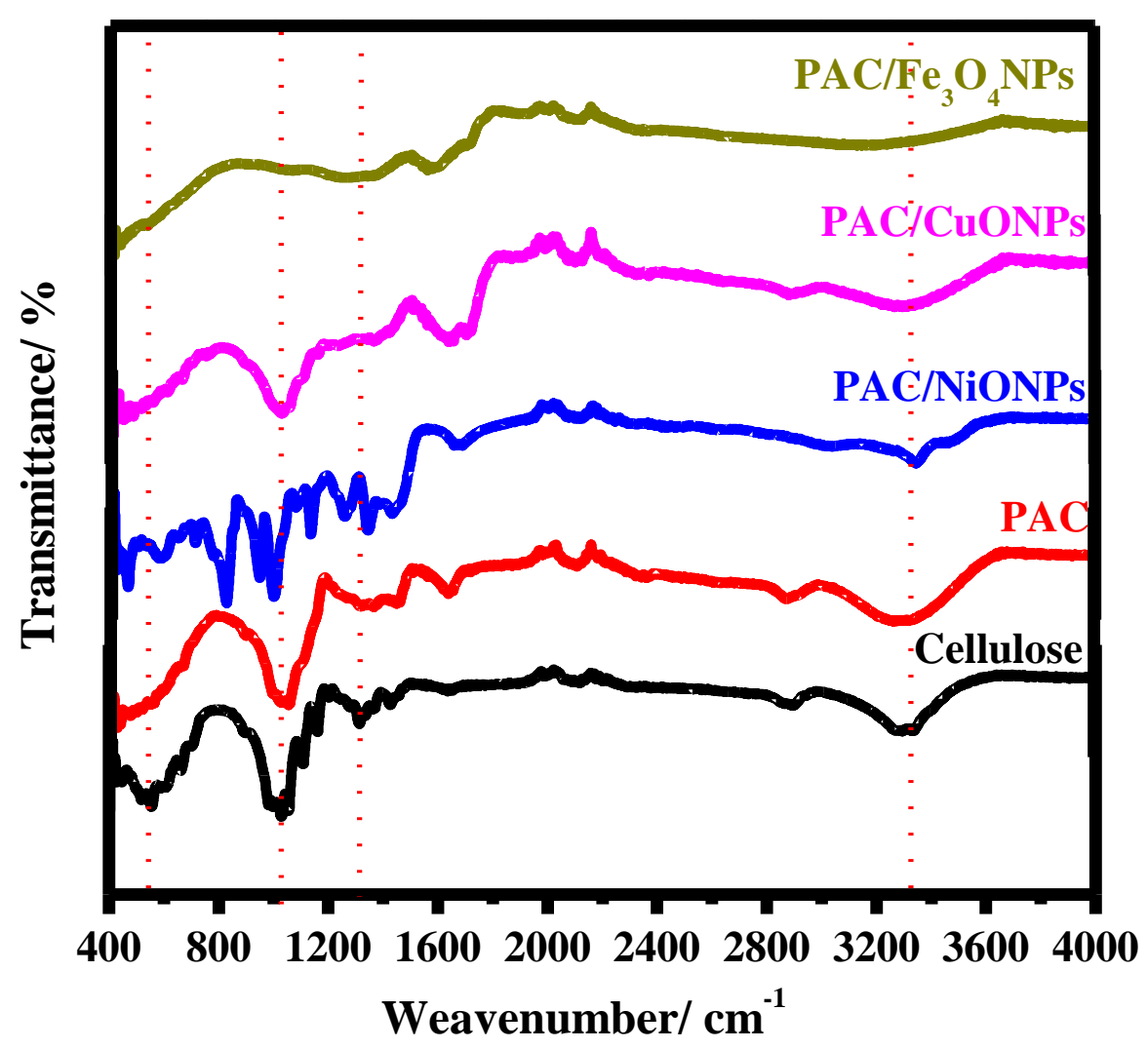

Figure 1. FTIR spectral analysis of cellulose, primary aminated modified cellulose (PAC), $\mathrm{PAC} / \mathrm{NiONPs}, \mathrm{PAC} / \mathrm{CuONPs}$ and $\mathrm{PAC} / \mathrm{Fe}_{3} \mathrm{O}_{4} \mathrm{NPs}$ nanocomposites.

\subsubsection{XRD}

The crystal structure of PAC and PAC/MONPs has been studied using X-ray diffraction. The size of the PAC/MONPs crystal has been determined utilizing Scherer's equation according to the following equation:

$$
D_{\mathrm{nm}}=\frac{k \lambda}{\beta \cos \theta}
$$

where $D_{\mathrm{nm}}$ represents the crystal size (in $\mathrm{nm}$ ), $k=0.890$ represents the constant of Scherrer, $\lambda=0.15425 \mathrm{~nm}$ symbolizes the wavelength of $\mathrm{X}$-ray, $\beta$ characterizes the complete thickness at a partial maximum of the band (FWHM), and $\theta$ represents the Bragg angle [54]. Figure 2 demonstrates the crystallographic behavior of the PAC, PAC/NiONPs, PAC/CuONPs, and $\mathrm{PAC} / \mathrm{Fe}_{3} \mathrm{O}_{4} \mathrm{NPs}$, correspondingly. Crystalline bands for unmodified cellulose were detected about $2 \theta$ of $16.0^{\circ}$ and $22.0^{\circ}$, consistent with (110) and (200) planes according to the literature [55]. In PAC, a variation in the crystallinity occurred due to the disappearance of a peak at $2 \theta$ of $16^{\circ}$, and a peak at $22^{\circ}$ was shifted to approximately $25.8^{\circ}$. Therefore, PAC/MONPs display remarkable alterations in the PAC patterns. As displayed in Figure 2, the presence of NiONPs (apparently of PAC) was identified by bands at $2 \theta$ of $44.1^{\circ}$ and 
$60.8^{\circ}$, which are known as peaks of cubic NiONPs crystal conforming to crystal planes (200), as well as (220), correspondingly. On the other hand, a band at $2 \theta$ of $33.5^{\circ}$ is recognized as $\mathrm{Ni}_{2} \mathrm{O}_{3}$ (004), which is consistent with the data (JCPDS-Card 47-1049) [56]. Nevertheless, NiONPs did not change the crystal structure of PAC because the peak at $25.8^{\circ}$ had not disappeared. Moreover, Figure 2 shows a robust and acute peak at $2 \theta$ of $28.1^{\circ}$ (112) for cubic copper oxide crystallites. Correspondingly, weak bands at $2 \theta$ of $32^{\circ}, 35.5^{\circ}$ and $38.6^{\circ}$ are allocated to (110), (002) and (111) crystal level surface (JCPDS-Card 033-0480) [57,58]. The PAC crystal construction crashed, and thus the peak at $25.9^{\circ}$ was completely repelled due to a good interaction of $\mathrm{Cu}$ with PAC. Finally, Figure 2 displays the XRD configuration of $\mathrm{PAC} / \mathrm{Fe}_{3} \mathrm{O}_{4}$ that represents feeble diffraction bands at $2 \theta$ of $28.6^{\circ}$ and $35.6^{\circ}$, that are allocated to (220) and (311) planes [59]. The considered typical crystal size of MONPs according to Equation (1) was 9-15 nm. Meanwhile, these results were well-matched with the results obtained from SAED analysis.
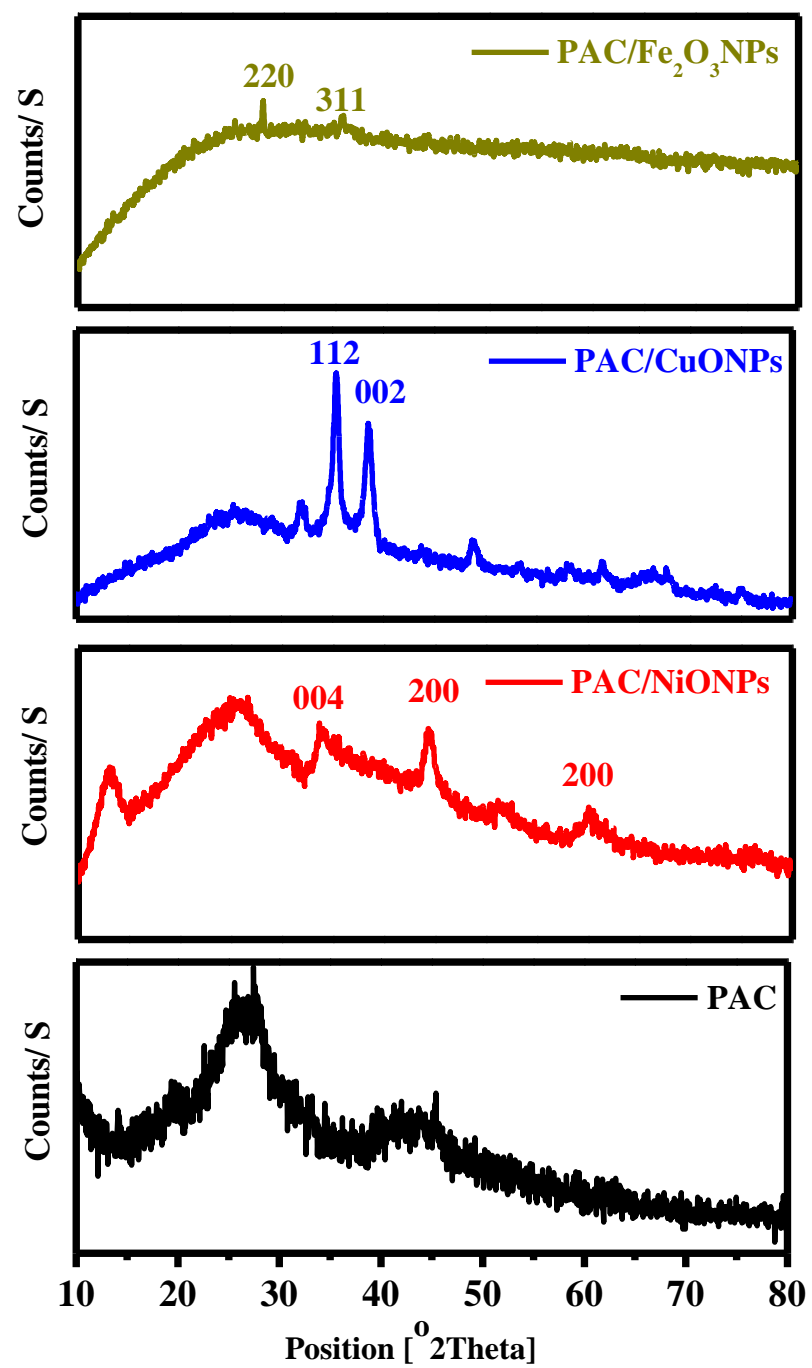

Figure 2. X-ray diffraction (XRD) pattern of PAC, $\mathrm{PAC} / \mathrm{NiONPs}$, $\mathrm{PAC} / \mathrm{CuONPs}$ and $\mathrm{PAC} / \mathrm{Fe}_{3} \mathrm{O}_{4} \mathrm{NPs}$ nanocomposites.

\subsubsection{FE-SEM and EDX}

Figure 3A-D shows the scanning electron microscope and EDX for unmodified cellulose and amino cellulose samples without and with metal oxide nanoparticles. It can be seen from the SEM micrographs that unmodified cellulose surface is plain and uniform in size, plated formed, and with a strip-like structure. Furthermore, it is seen that the morphology structure of unmodified cellulose has changed after modification with the 
primary amine. PAC samples were unpredictably wrinkled with light spots of spongy structures. This property was apparently attributed to the presence of an amino group. In addition, Figure $3 \mathrm{C}-\mathrm{E}$ shows that no agglomeration and uniform spreading of MONPs occurs inside the PAC by means of cubic form, as detected in Figure 3C-E. In conjunction with the EDX investigation, the data confirmed the formation of nanocomposites and the spectra display the occurrence of NiONPs (signals at 7.80 and 8.40), CuONPs (signals at 8.0 and $9.0 \mathrm{eV}$ ), $\mathrm{Fe}_{3} \mathrm{O}_{4} \mathrm{NPs}$ (signals at 6.20 and $7.0 \mathrm{eV}$ ), while no other impurity was identified in the spectrum of the sample.
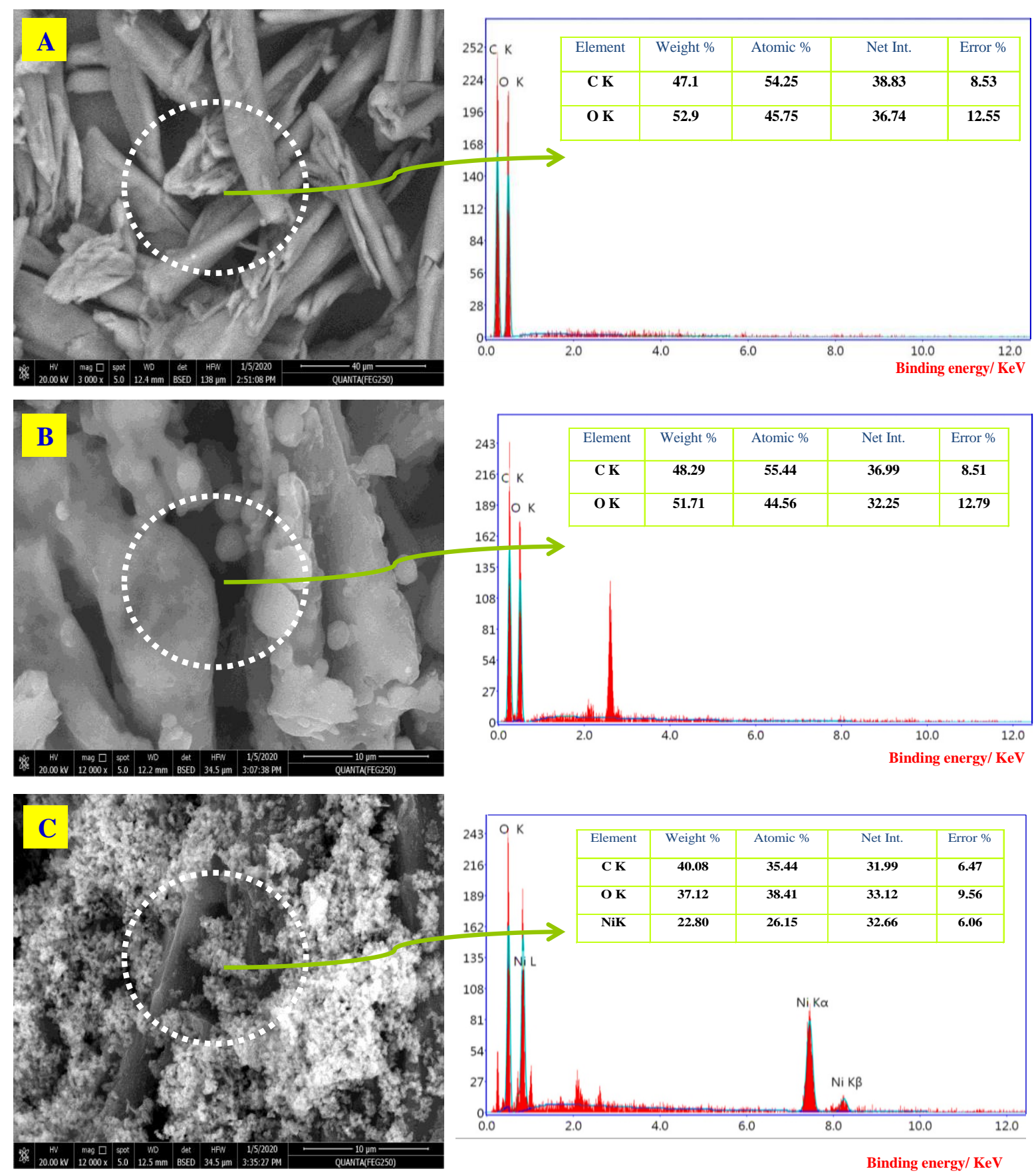

Figure 3. Cont. 

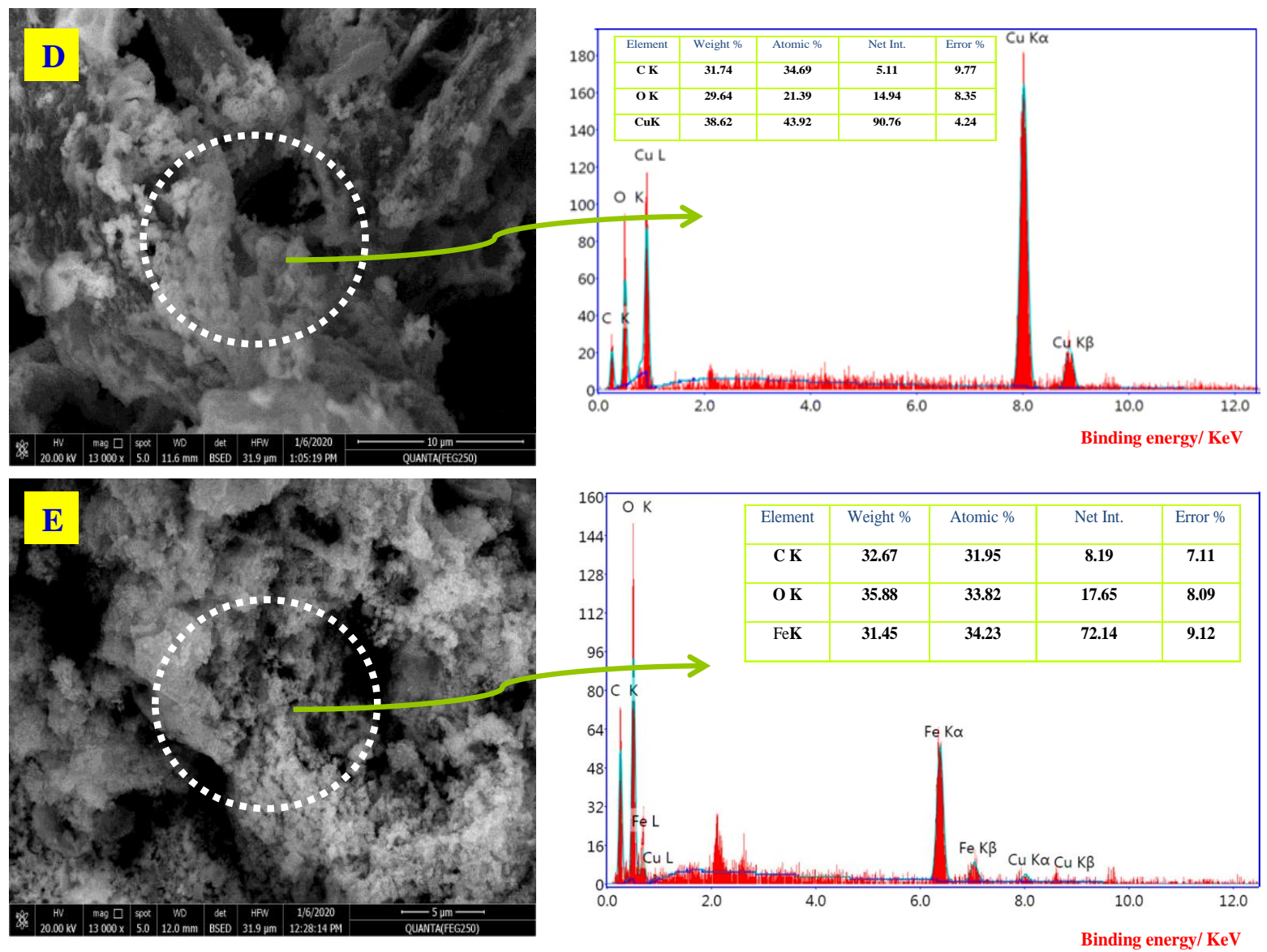

Figure 3. Field-emission scanning electron microscopy (FE-SEM) and energy-dispersive X-ray spectroscopy (EDX) spectra of (A) cellulose, (B) PAC, (C) PAC/NiONPs, (D) PAC/CuONPs and (E) PAC $/ \mathrm{Fe}_{3} \mathrm{O}_{4} \mathrm{NPs}$ nanocomposites.

\subsubsection{TEM and SAED Analyses}

TEM is a procedure utilized to break down the distribution and diameter of fabricated MONPs in PAC. Figure $4 \mathrm{~A}-\mathrm{C}$ shows the TEM and SAED of prepared PAC/NiONPs, $\mathrm{PAC} / \mathrm{CuONPs}$, and $\mathrm{PAC} / \mathrm{Fe}_{3} \mathrm{O}_{4} \mathrm{NPs}$, individually. TEM pictures show level and smooth films of MONPs surfaces without any conglomeration. Moreover, it is seen that MONPs showed up as round dim spots and consistently scattered inside the PAC. Besides, the size dispersion of the MONPs is generally restricted and their diameter was found around 10, 23, and $25 \mathrm{~nm}$ for NiONPs, CuONPs, and $\mathrm{Fe}_{3} \mathrm{O}_{4} \mathrm{NPs}$, separately. Additionally, the SAED was applied to portray the qualities and structures of the MONPs existing on the PAC interface (Figure $4 \mathrm{~A}-\mathrm{C}$ ). The chosen region for the diffraction design with the allocated Miller records has firmly coordinated the qualities acquired by XRD. The SAED pictures demonstrated the translucent highlights of the readied PAC/MONPs and the presence of the MONPs on the PAC interface, and these MONPs crystals help with dispersing the electron radiates.

\subsection{Corrosion Protection Measurements}

\subsubsection{Weight-Loss Investigations and Influence of Temperature}

The values of corrosion rate (CR) and inhibition capacity intended from the weight loss measurements at $303 \mathrm{~K}$ are presented in Figure 5. As can be observed from Figure 5, the inhibition power increases from $42.2,46.1,50.3$ and $56.5 \%$ to $89.5,93.4,96.2$ and $98.8 \%$, and the corrosion rate decreases from $0.02823,0.02616,0.02416$ and $0.02101 \mathrm{mg} \mathrm{cm}^{-2} \mathrm{~h}^{-1}$ to $0.0053,0.004,0.00201$ and $0.00069 \mathrm{mg} \mathrm{cm}^{-2} \mathrm{~h}^{-1}$ as the concentration of PAC, PAC/nCuO, $\mathrm{PAC} / \mathrm{nFe}_{3} \mathrm{O}_{4}$ and $\mathrm{PAC} / \mathrm{nNiO}$ increases from 25 to $250 \mathrm{ppm}$, respectively. An increment 
in the concentration of inhibitors suppressed C-steel corrosion in molar $\mathrm{HCl}$ solution and consequently provided higher surface coverage. Furthermore, the PAC $/ \mathrm{nNiO}$ shows excellent corrosion protection features, which could be observed from higher inhibition power $(98.8 \%)$ and the lower corrosion rate $\left(0.00069 \mathrm{mg} \mathrm{cm}^{-2} \mathrm{~h}^{-1}\right)$ by comparing with that of $\mathrm{PAC}, \mathrm{PAC} / \mathrm{nCuO}$ and $\mathrm{PAC} / \mathrm{nFe}_{3} \mathrm{O}_{4}$.
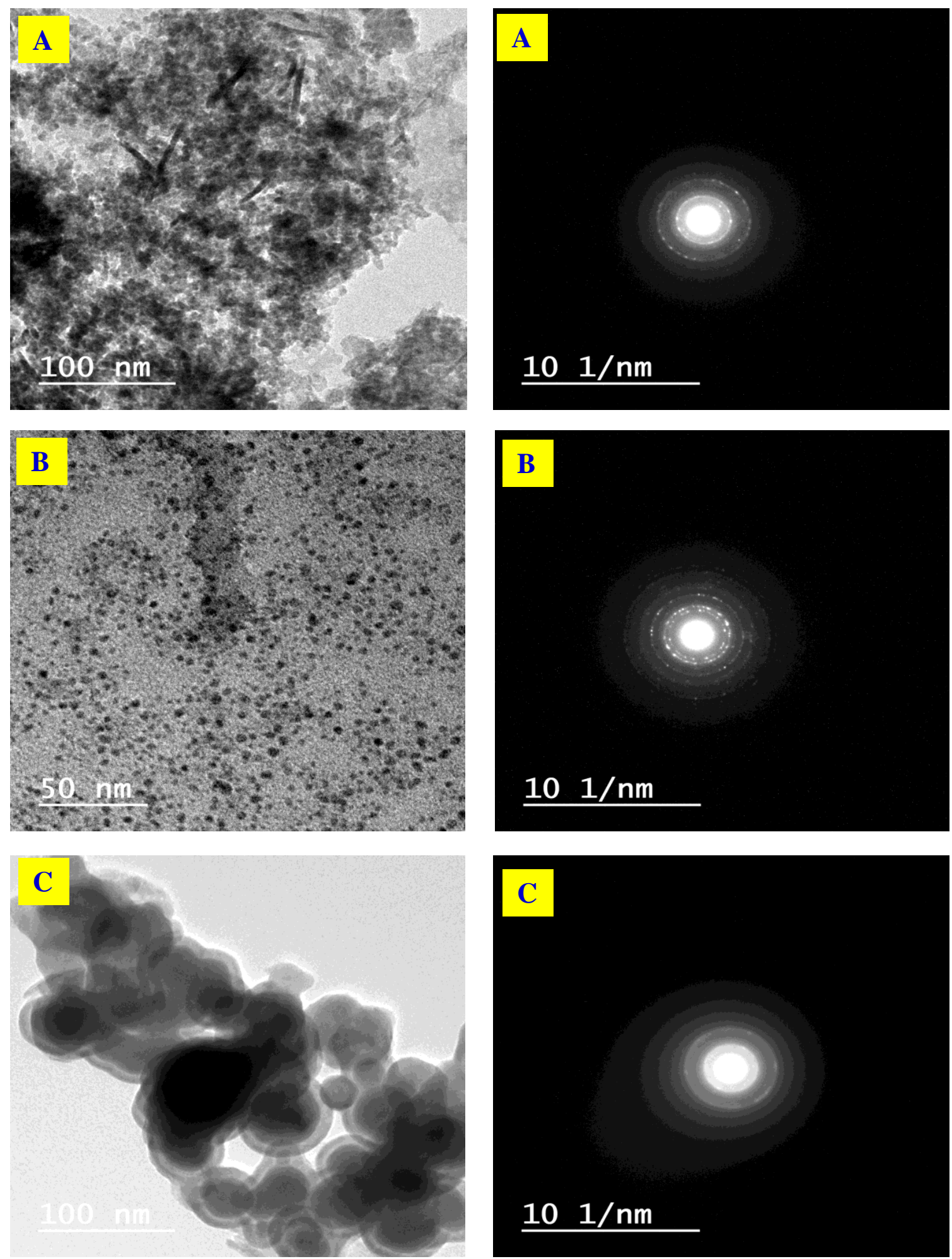

Figure 4. Transmission electron microscope (TEM) and selected area diffraction pattern (SAED) of (A) PAC/NiONPs, (B) PAC/CuONPs and (C) PAC $/ \mathrm{Fe}_{3} \mathrm{O}_{4} \mathrm{NPs}$ nanocomposites. 


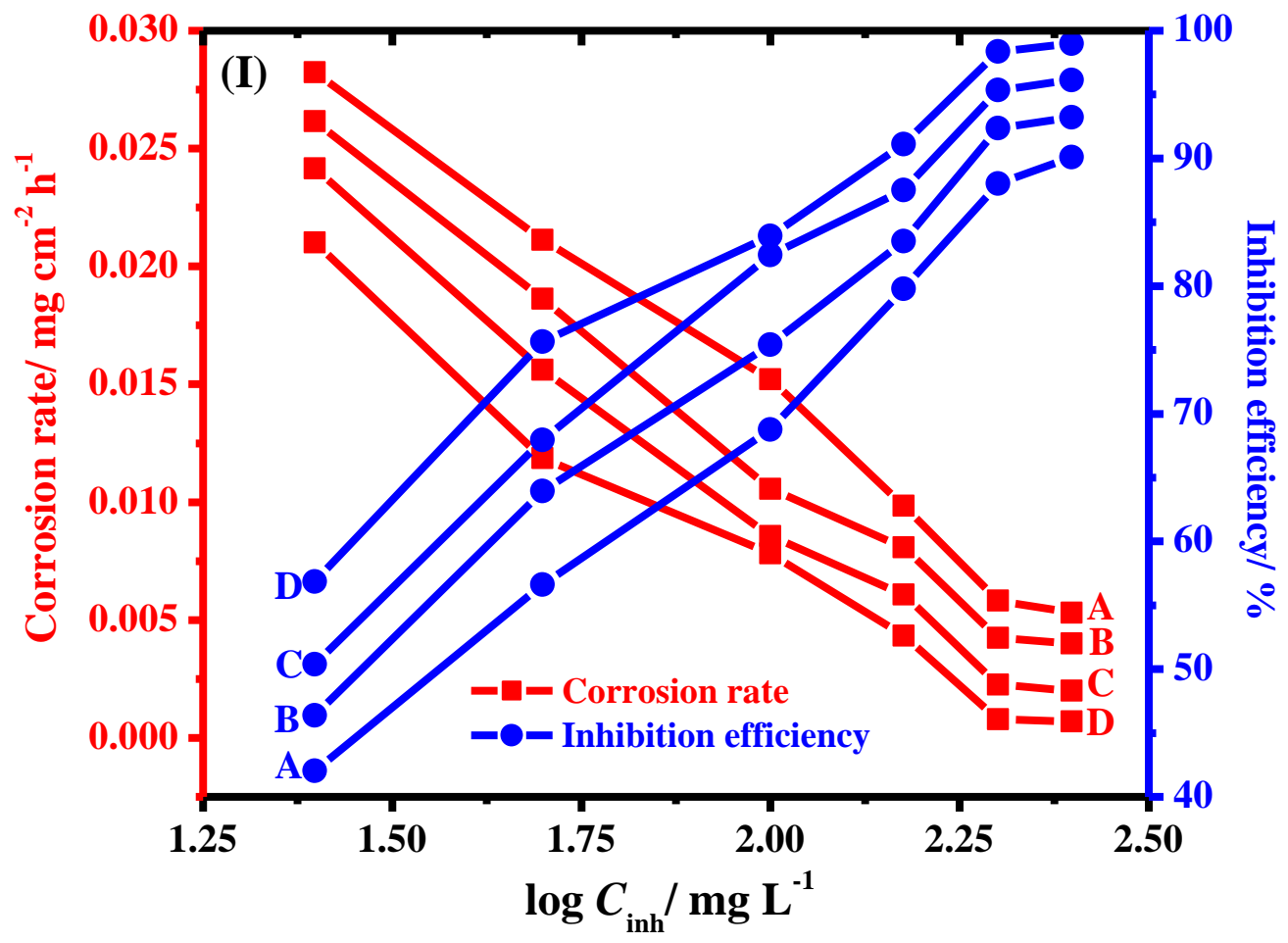

Figure 5. Change of corrosion rate and inhibition efficiency of C-steel in $1.0 \mathrm{M} \mathrm{HCl}$ solution with concentration of (A) PAC, (B) PAC/CuONPs/, (C) PAC $/ \mathrm{Fe}_{3} \mathrm{O}_{4} \mathrm{NPs}$ and (D) PAC/NiONPs at $303 \mathrm{~K}$.

To study the temperature impact on the protected characteristic of PAC, $\mathrm{PAC} / \mathrm{nCuO}$, $\mathrm{PAC} / \mathrm{nFe}_{3} \mathrm{O}_{4}$, and $\mathrm{PAC} / \mathrm{nNiO}$ inhibitors, weight loss measurements were performed at a temperature range of $30-60{ }^{\circ} \mathrm{C}$ for $48 \mathrm{~h}$. Figure $6 \mathrm{~A}, \mathrm{~B}$ show the corrosion rate (A) and protection efficiency (B) of C-steel in hydrochloric acid in the existence of $250 \mathrm{ppm}$ PAC, $\mathrm{PAC} / \mathrm{CuONPs}, \mathrm{PAC} / \mathrm{Fe}_{3} \mathrm{O}_{4} \mathrm{NPs}$, and PAC/NiONPs inhibitors at various temperatures. The corrosion rate values of the blank and inhibited C-steel specimens in $\mathrm{HCl}$ solution increment when the temperature rises; however, the increased amplitude of $\mathrm{PAC} / \mathrm{Fe}_{3} \mathrm{O}_{4} \mathrm{NPs}$, and PAC/NiONPs is small. In the inhibited solutions containing PAC and PAC/nCuO inhibitors, the inhibition capacity first increases and then diminishes. The decrease in the protection power could be related to the desorption of PAC and PAC/CuONPs from the $\mathrm{C}$-steel interface at a higher temperature. This phenomenon indicates that, at a higher temperature, PAC and PAC/CuONPs molecules fundamentally adsorb on the C-steel surface by physisorption [60]. On the other hand, the protection capacity of PAC/NiONPs (Figure $6 \mathrm{~B}, \mathrm{C}$ ) increases from $98.1 \%$ to $99.3 \%$ with a rise in temperature. In addition, the protection capacity of PAC/NiONPs at a higher temperature is $\sim 99.3 \%$, indicating that the whole C-steel surface is nearly entirely wrapped by the protective film. This is principally related to its small size and high density of ground boundary enabling good adhesion, which allows an excellent physical coverage of the metal surface and thus higher protection capacity [61]. By examining the change of inhibition power of PAC/NiONPs with the temperature (Figure 6B), it can be concluded that chemisorption plays a significant function in the process of adsorption [62]. 

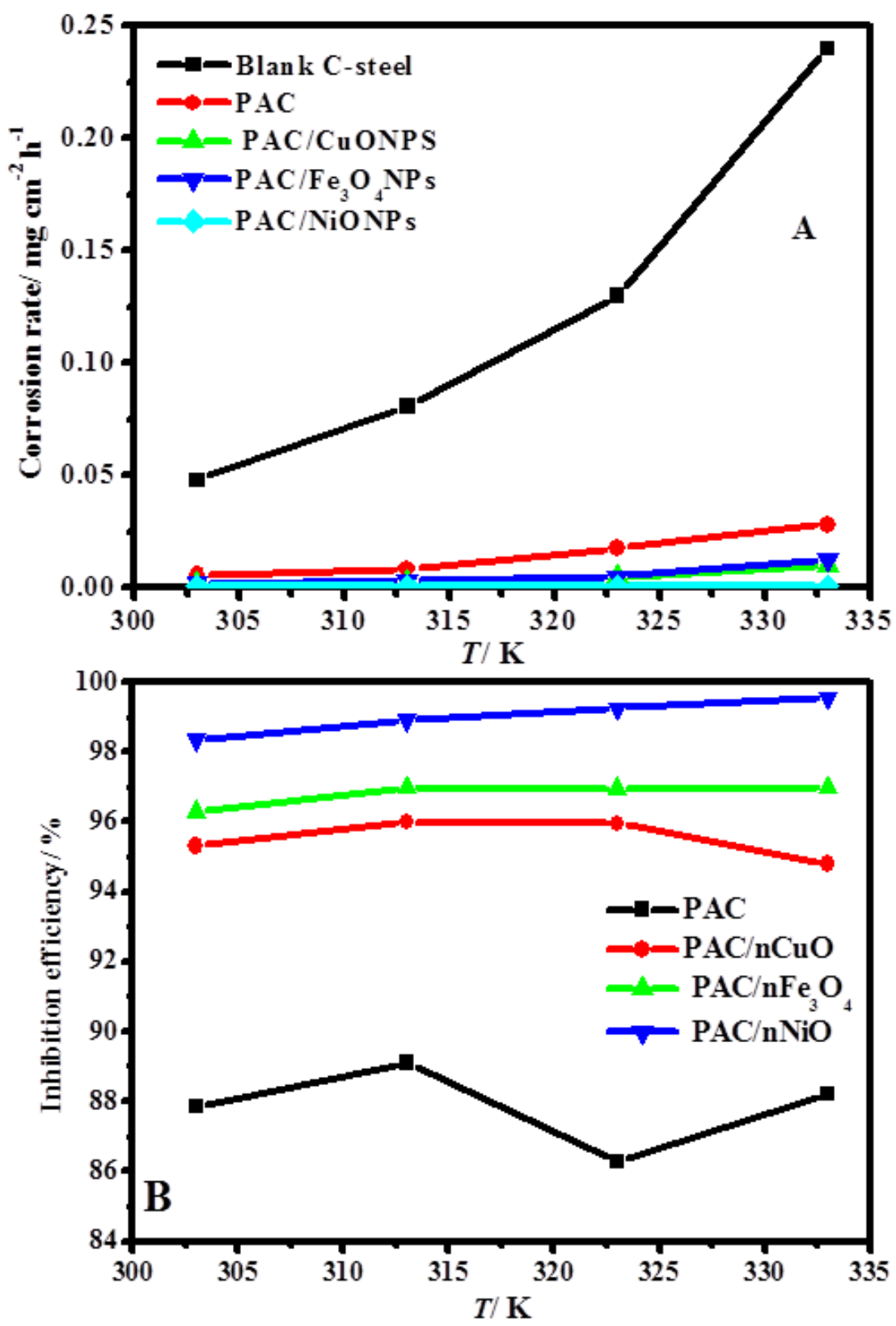

Figure 6. Corrosion rate (A) and inhibition efficiency (B) of C-steel in $1.0 \mathrm{M} \mathrm{HCl}$ solution containing 250 ppm of inhibitors at various temperatures.

\subsubsection{Potentiodynamic Polarization Study (PDP)}

This test was accomplished to obtain information on the kinetics and the corrosion mitigation action of the as-synthesized nanocomposites on the C-steel substrate. The achieved PDP profiles for C-steel in 1.0 M hydrochloric acid in the absence and existence of various PAC and PAC/MONPs nanocomposite doses are displayed in Figure 7. Extrapolation of Tafel fit was applied to compute electrochemical indices including corrosion potential $\left(E_{\text {cor }}\right)$, corrosion current density $\left(i_{\text {cor }}\right)$, and anodic and cathodic Tafel slopes $\left(\beta_{\mathrm{c}}\right.$ and $\left.\beta_{\mathrm{a}}\right)$. The consequences of PDP studies are documented in Table 1 . The protection capacity $\left(\eta_{\mathrm{P}} / \%\right)$ and surface coverage $(\theta)$ were also intended based on Equation (2) [62] and the obtained results are displayed in Table 1 :

$$
\eta_{\mathrm{P}} / \%=\left(\frac{i_{\mathrm{cor}}^{0}-i_{\mathrm{cor}}^{i}}{i_{\mathrm{cor}}^{0}}\right) \times 100=\theta \times 100
$$


where $i_{\text {cor }}^{0}$ and $i_{\text {cor }}^{i}$ are the values of $i_{\text {cor }}$ in blank and inhibited medium, respectively. From Figure 7, both the anodic and cathodic branches minimized methodically with a rise in the dose of the PAC and PAC/MONPs nanocomposites, lacking much modification in the anodic and cathodic slopes.

The modification in $E_{\text {cor }}$ continued in between $\Delta E= \pm 13 \mathrm{mV}$ with respect to the uninhibited system; accordingly, the PAC and PAC/MONPs nanocomposites might be categorized as inhibitors of mixed-type [63-75]. When the PAC and PAC/MONPs nanocompos-

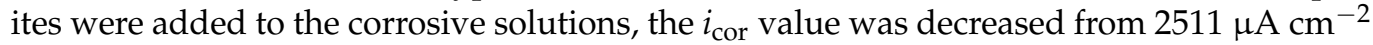
to $298.8,170.7,97.9$ and $35.1 \mu \mathrm{A} \mathrm{cm}{ }^{-2}$ in the presence of higher dose $\left(250 \mathrm{mg} \mathrm{L}^{-1}\right)$ for PAC, $\mathrm{PAC} / \mathrm{CuONPs}, \mathrm{PAC} / \mathrm{Fe}_{3} \mathrm{O}_{4} \mathrm{NPs}$ and $\mathrm{PAC} / \mathrm{NiONPs}$, respectively. These findings displayed that the fabricated PAC/MONPs nanocomposites can be applied as premium corrosion inhibitors for C-steel in hydrochloric acid solution, and the MONPs $\left(\mathrm{Fe}_{3} \mathrm{O}_{4}, \mathrm{CuO}\right.$ and $\mathrm{NiO}$ ) played a significant function in corrosion protection. Additionally, it is remarkable in Table 1 that the $\eta_{\mathrm{P}} / \%$ values of the four nanocomposites followed the order of $\eta_{\mathrm{P}}$ (PAC) $>\eta_{\mathrm{P}}(\mathrm{PAC} / \mathrm{CuONPs})>\eta_{\mathrm{P}}\left(\mathrm{PAC} / \mathrm{Fe}_{3} \mathrm{O}_{4} \mathrm{NPs}\right)>\eta_{\mathrm{P}}(\mathrm{PAC} / \mathrm{NiONPs})$, with the maximum protection capacity of $88.1 \%, 93.2 \%, 96.1 \%$ and $98.6 \%$, respectively, and the investigational findings were in agreement with those achieved by the weight-loss method. The rise in $\eta_{\mathrm{P}} / \%$ with an increase in inhibitor dose could be associated with an increment in the number of adsorbed inhibitor species at a metal/solution surface, therefore leading to a rise in the surface coverage $(\theta)$ value.

Table 1. PDP parameters for C-steel in molar hydrochloric acid without and with different concentrations of the as-prepared nanocomposite inhibitors at $50{ }^{\circ} \mathrm{C}$.

\begin{tabular}{|c|c|c|c|c|c|c|c|}
\hline Inhibitor Code & $\begin{array}{c}C_{\mathrm{inh}} / \\
\mathrm{mg} \mathrm{L}^{-1}\end{array}$ & $\begin{array}{l}i_{\text {cor }} \pm \mathrm{SD} / \\
\mu \mathrm{A} \mathrm{cm} \mathrm{cm}^{-2}\end{array}$ & $\begin{array}{c}-E_{\text {cor }} / \\
\text { V (SCE) }\end{array}$ & $\begin{array}{c}\beta_{\mathrm{a}} l \\
\mathrm{~V} \mathrm{dec}^{-1}\end{array}$ & $\begin{array}{c}-\beta_{\mathrm{c}} / \\
\mathrm{V} \mathrm{\textrm {dec } ^ { - 1 }}\end{array}$ & $\theta$ & $\begin{array}{c}\eta_{\mathrm{P}} / \\
\%\end{array}$ \\
\hline Blank & 0.0 & $2511+195$ & -0.416 & 0.081 & 0.161 & - & - \\
\hline \multirow{6}{*}{ PAC } & 25 & $1453.8 \pm 122$ & -0.414 & 0.088 & 0.176 & 0.421 & 42.1 \\
\hline & 50 & $1089.7 \pm 105$ & -0.412 & 0.093 & 0.176 & 0.566 & 56.6 \\
\hline & 100 & $785.9 \pm 65$ & -0.411 & 0.095 & 0.173 & 0.687 & 68.7 \\
\hline & 150 & $509.7 \pm 43$ & -0.426 & 0.084 & 0.174 & 0.797 & 79.7 \\
\hline & 200 & $344.1 \pm 23$ & -0.425 & 0.087 & 0.178 & 0.863 & 86.3 \\
\hline & 250 & $298.8 \pm 11$ & -0.418 & 0.091 & 0.18 & 0.881 & 88.1 \\
\hline \multirow{6}{*}{ PAC/CuONPs } & 25 & $1345.8 \pm 113$ & -0.410 & 0.095 & 0.179 & 0.464 & 46.4 \\
\hline & 50 & $906.4 \pm 86$ & -0.405 & 0.092 & 0.182 & 0.639 & 63.9 \\
\hline & 100 & $617.7 \pm 56$ & -0.425 & 0.089 & 0.176 & 0.754 & 75.4 \\
\hline & 150 & $414.3 \pm 34$ & -0.420 & 0.094 & 0.182 & 0.835 & 83.5 \\
\hline & 200 & $193.3 \pm 16$ & -0.422 & 0.087 & 0.185 & 0.923 & 92.3 \\
\hline & 250 & $170.7 \pm 10$ & -0.416 & 0.091 & 0.181 & 0.932 & 93.2 \\
\hline \multirow{6}{*}{$\mathrm{PAC} / \mathrm{Fe}_{3} \mathrm{O}_{4} \mathrm{NPs}$} & 25 & $1247.9 \pm 102$ & -0.403 & 0.095 & 0.174 & 0.503 & 50.3 \\
\hline & 50 & $806.1 \pm 77$ & -0.423 & 0.087 & 0.178 & 0.679 & 67.9 \\
\hline & 100 & $441.9 \pm 41$ & -0.430 & 0.092 & 0.176 & 0.824 & 82.4 \\
\hline & 150 & $313.8 \pm 26$ & -0.410 & 0.092 & 0.174 & 0.875 & 87.5 \\
\hline & 200 & $118.1 \pm 12$ & 0.407 & 0.089 & 0.177 & 0.953 & 95.3 \\
\hline & 250 & $97.9 \pm 8$ & -0.412 & 0.093 & 0.183 & 0.961 & 96.1 \\
\hline \multirow{6}{*}{ PAC/NiONPs } & 25 & $1084.7 \pm 97$ & -0.425 & 0.093 & 0.174 & 0.568 & 56.8 \\
\hline & 50 & $612.6 \pm 51$ & -0.432 & 0.094 & 0.181 & 0.756 & 75.6 \\
\hline & 100 & $404.2 \pm 37$ & -0.413 & 0.095 & 0.18 & 0.839 & 83.9 \\
\hline & 150 & $223.5 \pm 18$ & -0.408 & 0.088 & 0.181 & 0.911 & 91.1 \\
\hline & 200 & $67.8 \pm 6$ & -0.411 & 0.091 & 0.176 & 0.973 & 97.3 \\
\hline & 250 & $35.1 \pm 3$ & -0.415 & 0.093 & 0.179 & 0.986 & 98.6 \\
\hline
\end{tabular}



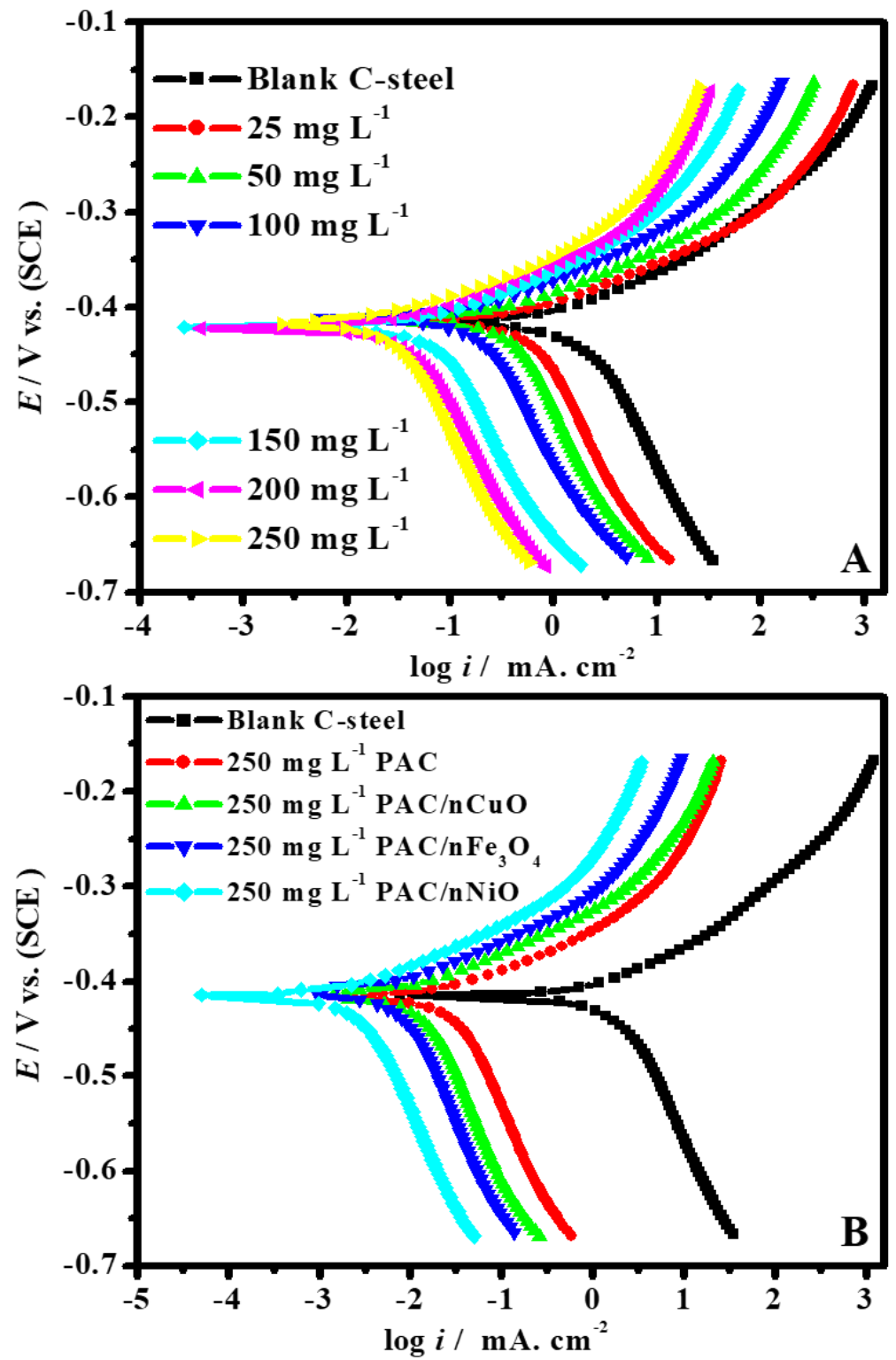

Figure 7. Tafel polarization profiles for C-steel in $1.0 \mathrm{M} \mathrm{HCl}$ solution without and with different concentrations of PAC (A) and in the presence of $250 \mathrm{mg} \mathrm{L}^{-1}$ of different nanocomposite inhibitors at $50{ }^{\circ} \mathrm{C}(\mathbf{B})$.

\subsubsection{EIS Studies}

In order to confirm the outcomes from the PDP and weight loss methods and fulfill more data about the mechanism of corrosion processes, the EIS investigation of C-steel in 1.0 M hydrochloric acid with different concentrations of PAC and PAC/MONPs nanocomposites was completed. Figure 8 represents the impedance plots for the working electrode in $\mathrm{HCl}$ solution: (A) Nyquist in the absence and existence of a various concentrations of PAC, (B) Nyquist in the absence and occurrence of $250 \mathrm{ppm}$ of different nanocomposite inhibitors, (C) Bode and (D) phase angle representations in the absence and occurrence of a different concentration of PAC at $323 \mathrm{~K}$. The Nyquist profiles obviously reveal that a rise in nanocomposites concentration (all individual $\mathrm{PAC}, \mathrm{PAC} / \mathrm{nCuO}, \mathrm{PAC} / \mathrm{nFe}_{3} \mathrm{O}_{4}$, and $\mathrm{PAC} / \mathrm{nNiO}$ nanocomposites) leads to an attendant improvement in the capacitance loops diameter. The non-ideal half-circle feature of the Nyquist diagram could be elucidated in terms of surface inhomogeneity owing to the development of an adsorbed film of the as-prepared nanocomposite collected with the corrosion product [66]. 

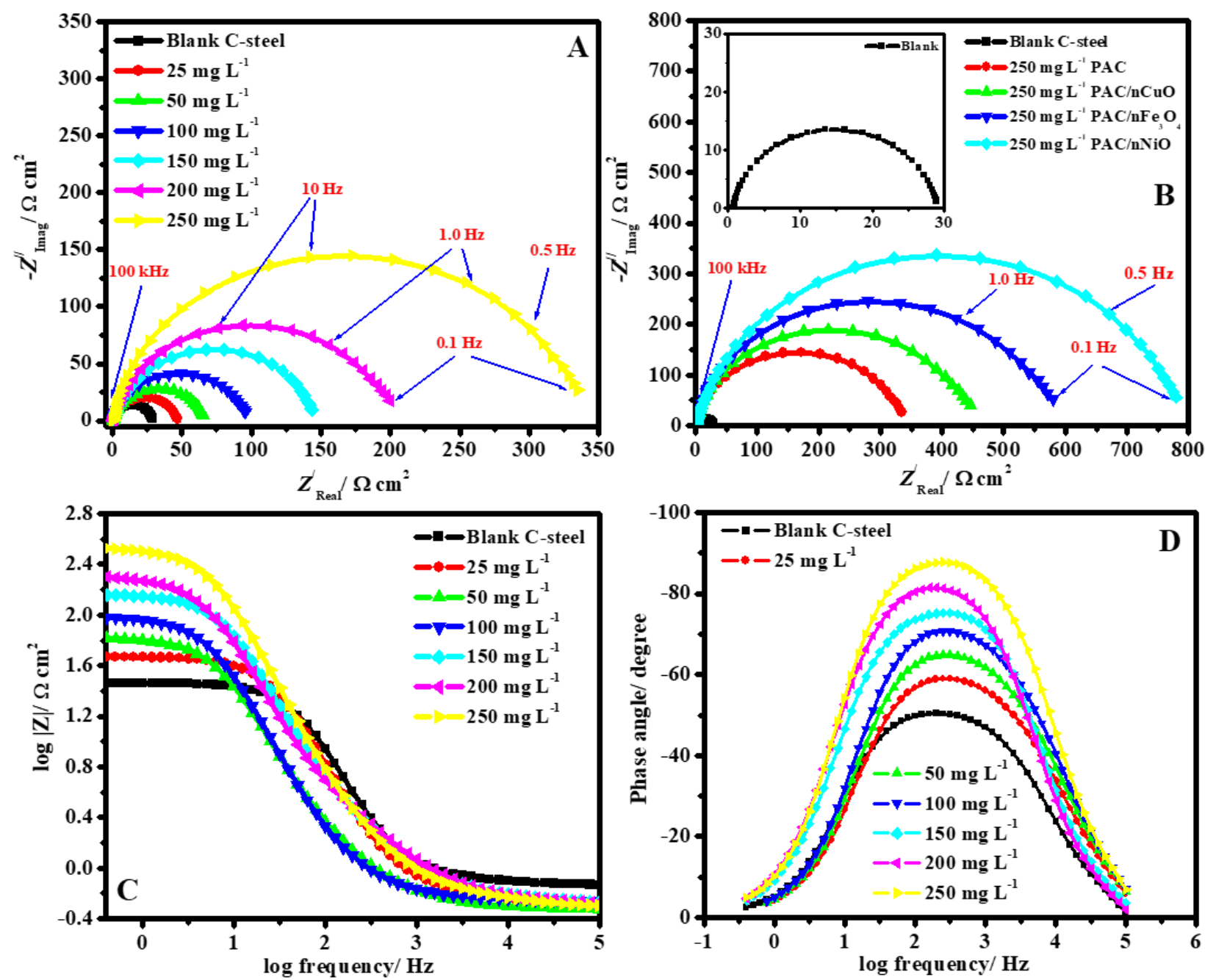

Figure 8. Impedance plots for C-steel in $1.0 \mathrm{M} \mathrm{HCl}$ solution; (A) Nyquist in the absence and presence of different concentration of PAC, (B) Nyquist in the absence and presence of $250 \mathrm{ppm}$ of different nanocomposite inhibitors, (C) Bode and (D) phase angle representations in the absence and presence of different concentration of PAC at $50{ }^{\circ} \mathrm{C}$.

The Nyquist profiles in the inhibited and uninhibited systems indicate the presence of a single capacitive loop and the lack of an inductive loop. The Bode diagram slope can deliver the ' $n$ ' parameter value (Table 2). It could be detected that the values of ' $n$ ' in the existence of PAC, $\mathrm{PAC} / \mathrm{CuO}, \mathrm{PAC} / \mathrm{Fe}_{3} \mathrm{O}_{4}$, and $\mathrm{PAC} / \mathrm{NiO}$ nanocomposites increased from 0.784 to 0.893 in comparison to the blank C-steel (0.701) specimen, which indicates that the $\mathrm{C}$-steel interface became more homogeneous with the existence of $\mathrm{PAC} / \mathrm{CuO}$, $\mathrm{PAC} / \mathrm{Fe}_{3} \mathrm{O}_{4}$, and $\mathrm{PAC} / \mathrm{NiO}$ nanocomposites. In the middle frequency area of the phase angle profile (Figure $8 \mathrm{D}$ ), the achieved values are within the range of $-51.1^{\circ}$ for the uninhibited C-steel to $-87.5^{\circ}$ with an increase in the PAC dose. In the circumstance of a perfect capacitor, the maxima phase angle in the middle frequencies scopes $-90^{\circ}$. Thus, the phase angle approach towards the values of the angle $-90^{\circ}$ in the occurrence of PAC shows an improvement in the capacitive routine in the existence of the nanocomposites [67].

The fitted EIS plots for the blank C-steel and inhibited system are displayed in Figure 9A,B. The impedance parameters recorded in Table 2 were obtained by fitting the accomplished EIS findings into the equivalent-circuit model for the phenomena depicted in Figure 9 insets (A, B) for uninhibited and inhibited systems, in which the electrolyte resistance $\left(R_{\mathrm{e}}\right)$ is shorted by a CPE (constant phase element) in place of the classical double layer capacitor $\left(C_{\mathrm{dl}}\right)$ that is in parallel to the resistance of polarization $\left(R_{\mathrm{p}}\right)$; wherein, the $R_{\mathrm{p}}$ is equal to the $R_{\mathrm{ct}}$ (the resistance of charge transfer) $+R_{\mathrm{e}}$ (the electrolyte resistance) for 
the blank C-steel specimen as designated previously [68]. In the presence of inhibitors (inhibited medium), the $R_{\mathrm{p}}$ is the shared influence of the resistance from the $R_{\mathrm{ct}}+R_{\mathrm{e}}+R_{\mathrm{f}}$ (the layer resistance designed on the surface of C-steel), which is in series to the parallel of $C_{\text {ads }}$ as capacitance because of the inhibitor adsorption layer [68]. The accuracy of the fitted EIS outcomes was appraised by the "fit goodness" chi-squared values $\left(\chi^{2}\right)$. It could be seen from Table 2 that the $\chi^{2}$ values are very lesser, which (in the order of $10^{-4}$ ) boosts the appropriateness of the equivalent circuit model for precise reproduction of the impedance findings. The relation between impedance and CPE is specified as [69]:

$$
Z_{\mathrm{CPE}}=\left[Y_{0}(j \omega)^{n}\right]^{-1}
$$

where $j$ characterizes the imaginary number, $Y_{0}$ represents a proportionality coefficient, and $n$ symbolize the phase shift. Regularly, CPE is transformed into the traditional endured elements resistance $(R)$, capacitor $(C)$, and inductance $(L)$ when $n=0,1$, and -1 , respectively. The protection capacity $\left(\eta_{\mathrm{E}} / \%\right)$ and surface coverage $(\theta)$ from the impedance data were computed from the following Equation [70]:

$$
\eta_{\mathrm{E}} / \%=\left[\frac{R_{\mathrm{p}}^{i}-R_{\mathrm{p}}^{0}}{R_{\mathrm{p}}^{i}}\right] \times 100=\theta \times 100
$$

where $R_{\mathrm{p}}^{0}$ and $R_{\mathrm{p}}^{i}$ represent the $R_{\mathrm{p}}$ in the uninhibited and inhibited mediums, respectively.

By inspection in Table 2, it was observed that the values of $R_{\mathrm{p}}$ increased intensely after the insertion of the as-prepared nanocomposites to the corrosive medium (i.e., $28.8 \Omega \mathrm{cm}^{2}$ vs. $353.9,457.2,614.4,804.5 \Omega \mathrm{cm}^{2}$ in the presence of $250 \mathrm{mg} \mathrm{L}^{-1}$ PAC, PAC/CuONPs, $\mathrm{PAC} / \mathrm{Fe}_{3} \mathrm{O}_{4} \mathrm{NPs}$ and PAC/NiONPs, respectively), demonstrating that these nanocomposites could efficiently impede the charge-transfer performance. Moreover, it should be indicated that the intended $\eta_{\mathrm{E}} / \%$ values of impedance spectroscopy increased with the nanocomposites addition, and, at the optimum dosage of $250 \mathrm{mg} \mathrm{L}^{-1}$ additives, the maximum protection power $\left(\eta_{\mathrm{E}}\right)$ reached $91.8 \%$ for PAC, 93.7\% for PAC/CuONPs, $95.3 \%$ for PAC $/ \mathrm{Fe}_{3} \mathrm{O}_{4} \mathrm{NPs}$ and $96.4 \%$ for PAC/NiONPs, respectively.

Table 2. Impedance parameters for C-steel in molar hydrochloric acid without and with different concentrations of the

\begin{tabular}{|c|c|c|c|c|c|c|c|c|c|}
\hline Inhibitor Codes & $C_{\mathrm{inh}} / \mathrm{mg} \mathrm{L}^{-1}$ & $R_{\mathrm{e}} / \Omega \mathrm{cm}^{2}$ & $R_{\mathrm{P}} / \Omega \mathrm{cm}^{2} \pm \mathrm{SD}$ & $C_{\mathrm{dl}} / \mathrm{F} \mathrm{cm}^{-2} \times 10^{-6}$ & $\begin{array}{c}Q_{\mathrm{CPE}} \\
Y_{0} / \mu \Omega^{-1} \mathrm{~s}^{\mathrm{n}} \mathrm{cm}^{-2}\end{array}$ & $n$ & $\chi^{2} \times 10^{-4}$ & $\theta$ & $\eta_{\mathrm{E}} / \%$ \\
\hline $1.0 \mathrm{M} \mathrm{HCl}$ & 0.0 & 0.69 & $28.8 \pm 2.1$ & 822.5 & 75.84 & 0.701 & 4.52 & - & - \\
\hline \multirow{6}{*}{ PAC } & 25 & 0.78 & $48.2 \pm 3.2$ & 310.8 & 27.22 & 0.784 & 3.72 & 0.402 & 40.2 \\
\hline & 50 & 0.73 & $69.1 \pm 4.3$ & 251.6 & 22.24 & 0.793 & 3.77 & 0.583 & 58.3 \\
\hline & 100 & 0.71 & $101.4 \pm 7.3$ & 140.8 & 12.39 & 0.872 & 3.81 & 0.715 & 71.5 \\
\hline & 150 & 0.89 & $150.3 \pm 11.5$ & 92.5 & 8.02 & 0.812 & 3.86 & 0.808 & 80.8 \\
\hline & 200 & 0.82 & $213.6 \pm 15.6$ & 81.6 & 6.44 & 0.862 & 4.01 & 0.865 & 86.5 \\
\hline & 250 & 0.98 & $353.9 \pm 21.7$ & 56.6 & 4.98 & 0.822 & 3.90 & 0.918 & 91.8 \\
\hline \multirow{6}{*}{ PAC/CuONPs } & 25 & 0.85 & $49.8 \pm 3.1$ & 245.8 & 21.51 & 0.793 & 3.77 & 0.422 & 42.2 \\
\hline & 50 & 0.81 & $74.2 \pm 5.2$ & 204.1 & 17.86 & 0.784 & 3.79 & 0.612 & 61.2 \\
\hline & 100 & 0.78 & $115.6 \pm 7.8$ & 128.3 & 11.30 & 0.803 & 3.81 & 0.751 & 75.1 \\
\hline & 150 & 0.97 & $189.4 \pm 9.5$ & 68.3 & 5.95 & 0.812 & 3.94 & 0.848 & 84.8 \\
\hline & 200 & 0.93 & $313.1 \pm 15.7$ & 54.1 & 3.76 & 0.889 & 3.97 & 0.908 & 90.8 \\
\hline & 250 & 1.07 & $457.2 \pm 24.3$ & 40.8 & 3.52 & 0.829 & 3.86 & 0.937 & 93.7 \\
\hline \multirow{6}{*}{$\mathrm{PAC} / \mathrm{Fe}_{3} \mathrm{O}_{4} \mathrm{NPs}$} & 25 & 0.81 & $51.7 \pm 3.9$ & 185.2 & 16.16 & 0.812 & 4.19 & 0.443 & 44.3 \\
\hline & 50 & 0.84 & $82.7 \pm 5.7$ & 126.6 & 11.06 & 0.825 & 4.14 & 0.652 & 65.2 \\
\hline & 100 & 0.89 & $142.5 \pm 8.4$ & 103.3 & 8.99 & 0.812 & 3.97 & 0.798 & 79.8 \\
\hline & 150 & 0.94 & $223.2 \pm 12.4$ & 55.8 & 6.56 & 0.822 & 3.55 & 0.871 & 87.1 \\
\hline & 200 & 1.02 & $374.1 \pm 18.9$ & 42.5 & 4.98 & 0.847 & 3.69 & 0.923 & 92.3 \\
\hline & 250 & 1.12 & $614.4 \pm 27.5$ & 30.1 & 2.67 & 0.851 & 4.04 & 0.953 & 95.3 \\
\hline \multirow{6}{*}{$\mathrm{PAC} / \mathrm{NiONPS}$} & 25 & 0.85 & $55.9 \pm 4.3$ & 152.5 & 11.18 & 0.852 & 4.26 & 0.485 & 48.5 \\
\hline & 50 & 0.87 & $97.3 \pm 6.2$ & 104.1 & 7.65 & 0.866 & 4.22 & 0.704 & 70.4 \\
\hline & 100 & 0.93 & $176.6 \pm 13.3$ & 85.3 & 6.19 & 0.852 & 4.04 & 0.837 & 83.7 \\
\hline & 150 & 0.98 & $271.7 \pm 17.2$ & 45.8 & 4.49 & 0.863 & 3.61 & 0.894 & 89.4 \\
\hline & 200 & 1.06 & $564.7 \pm 25.9$ & 35.2 & 3.40 & 0.889 & 3.76 & 0.949 & 94.9 \\
\hline & 250 & 1.17 & $804.5 \pm 56.4$ & 24.1 & 1.82 & 0.893 & 4.12 & 0.964 & 96.4 \\
\hline
\end{tabular}
as-prepared nanocomposite inhibitors at $50{ }^{\circ} \mathrm{C}$. 

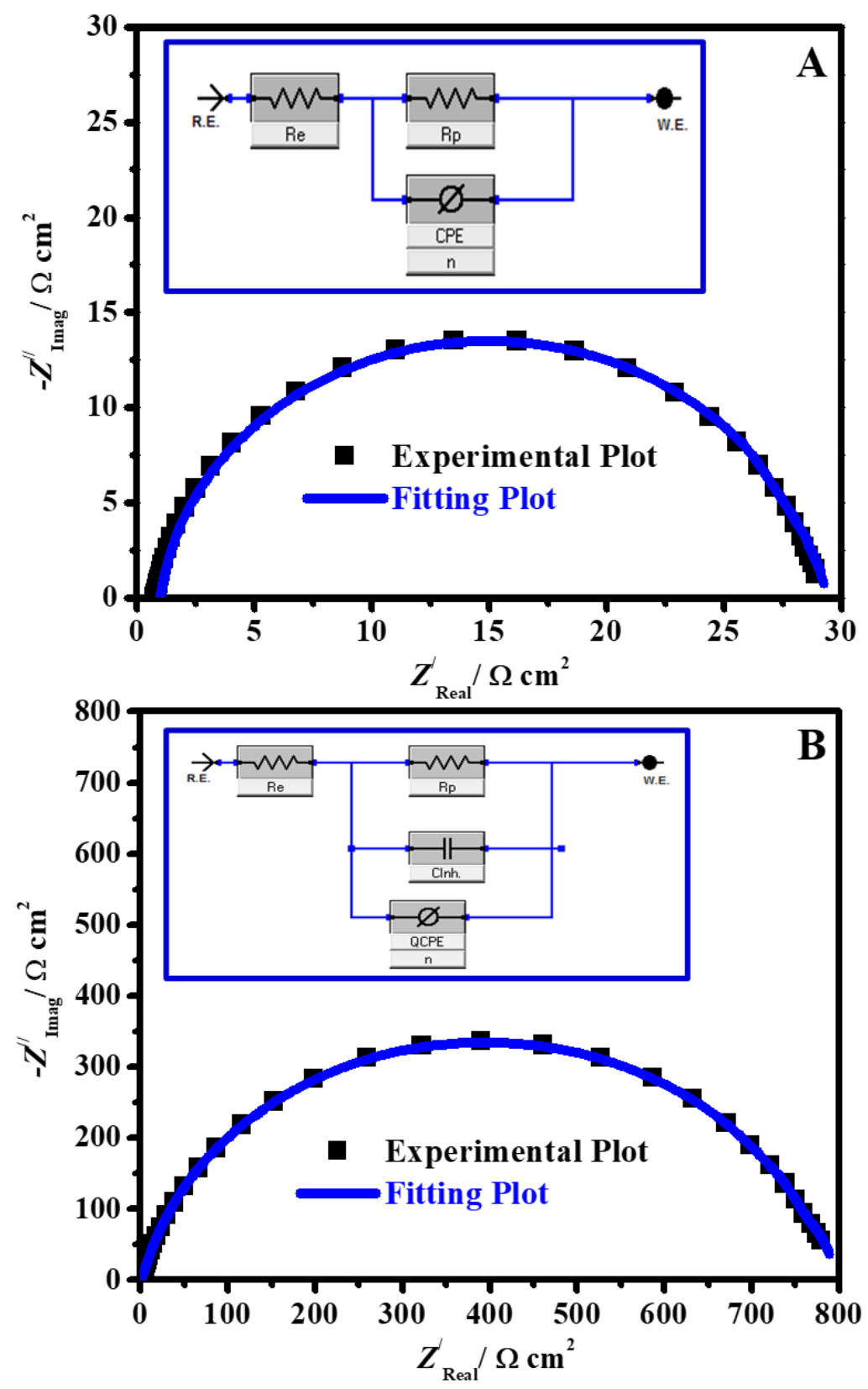

Figure 9. Experimental and fitted Nyquist results of C-steel in an uninhibited system (A) and an inhibited system (B) Inset equivalent circuits model for the phenomena.

Furthermore, Table 2 exhibits that the double layer capacitance values $\left(C_{\mathrm{dl}}\right)$ diminished regularly with an increment in nanocomposite dose. The degree of the decline in $C_{\mathrm{dl}}$ was larger for PAC $/ \mathrm{nNiO}$ nanocomposite. The idea of electrochemical $C_{\mathrm{dl}}$ was first presented by Helmholtz and then explained by Geary and Stern [71]. Various parameters including surface area available to ions $(A)$, the distance between the charged metal surface and the ion $(d)$, the vacuum permittivity $\left(\varepsilon_{0}\right)$ and the electrolyte dielectric constant $\left(\varepsilon_{0}\right)$ determine the $C_{\mathrm{dl}}$, based on the following Equation [71]:

$$
C_{\mathrm{dl}}=\frac{\varepsilon_{0} \varepsilon A}{d}
$$

An increase in composite dosage leads to a greater degree of $\theta$, and thus decreases the efficacious value of $A$. Furthermore, the nanocomposite species (PAC/MONPs) are 
adsorbed at the interface of steel $/ \mathrm{HCl}$, substituting water molecules and pre-adsorbed $\mathrm{Cl}^{-}$ ions. This shrinks the solution dielectric-constant of the abutment to the steel substrate. Meanwhile, the pre-adsorbed $\mathrm{Cl}^{-}$ions create the double layer prevalent away from the steel interface, the active double layer thickness rises [72]. All these features act accommodatingly in dropping the electrochemical $C_{\mathrm{dl}}$, per unit surface-area in the occurrence of PAC/MONPs additives. The different rates of corrosion-decreasing impacts were more predominant for $\mathrm{PAC} / \mathrm{NiO}$ nanocomposite, determining it the superior inhibitor. This is also apparent from the lesser $C_{\mathrm{dl}}$ and greater $R_{\mathrm{p}}$ values for PAC/NiONPs compared to that for PAC, PAC/CuONPs, and $\mathrm{PAC} / \mathrm{Fe}_{3} \mathrm{O}_{4} \mathrm{NPs}$ at the same conditions.

\subsection{Adsorption Consedrations}

The inhibitors diminish the $\mathrm{C}$-steel corrosion rate by adsorption at the electrode/medium surface, whereas the significant indices of interaction between the steel interface and inhibitor molecule could be achieved from the models of adsorption isotherm [60]. Inhibitor structure, metal nature and surface charge, corrosive solution type, and the distribution of molecular charge are aspects influencing inhibitors in adsorption routes [3]. With an increment in the investigated nanocomposite dose, the protection capacity is augmented. This point could be clarified by the adsorption of these nanocomposites on the C-steel interface. In the current report, the $\theta$ values were endeavored to be fitted into various isotherm models such as Temkin, Flory-Huggins, Langmuir, and Frumkin.

Adsorption isotherms of $\mathrm{PAC}, \mathrm{PAC} / \mathrm{CuO}, \mathrm{PAC} / \mathrm{Fe}_{3} \mathrm{O}_{4}$ and $\mathrm{PAC} / \mathrm{NiO}$ nanocomposites on $\mathrm{C}$-steel by their $\theta$ values as a function of PAC/MONPs dose in molar hydrochloric acid solution $\left(C_{\mathrm{inh}}\right)$ are displayed in Figure 10. The diagrams designate that all PAC, PAC/nCuO, $\mathrm{PAC} / \mathrm{nFe}_{3} \mathrm{O}_{4}$ and $\mathrm{PAC} / \mathrm{nNiO}$ nanocomposites follow a linear Langmuir model inclination, as straightforward lines were produced with regression coefficient values $\left(R^{2}\right) \sim 1$ (Table 3 ). The Langmuir model is specified by the next formula [4]:

$$
\frac{C_{\text {Inh }}}{\theta}=C_{\text {Inh }}+\frac{1}{K_{\text {ads }}}
$$

Table 3. Adsorption parameters derived from Langmuir model for C-steel in molar $\mathrm{HCl}$ for PAC /MONPs at $50^{\circ} \mathrm{C}$ using PDP outcomes.

\begin{tabular}{|c|c|c|c|c|}
\hline Inhibitor & $R^{2}$ & $S=$ slope & $K_{\text {ads }}\left(\mathrm{L} \mathrm{g}^{-1}\right)$ & $\Delta G_{\mathrm{ads}}^{0} / \mathrm{kJ} \mathrm{g}^{-1}$ \\
\hline PAC & 0.998 & 0.978 & 25.65 & -45.82 \\
\hline PAC/CuONPs & 0.998 & 0.942 & 30.30 & -46.26 \\
\hline $\mathrm{PAC} / \mathrm{Fe}_{2} \mathrm{O}_{3} \mathrm{NPs}$ & 0.999 & 0.929 & 37.03 & -46.79 \\
\hline PAC/NiONPs & 0.999 & 0.932 & 45.45 & -47.34 \\
\hline
\end{tabular}

Herein, $K_{\text {ads }}$ symbolizes the adsorption equilibrium constant and $\theta$ is measured from PDP studies. The $K_{\text {ads }}$ is connected with the standard free energy of adsorption $\left(\Delta G_{\text {ads }}^{0}\right)$, through Equation [5]:

$$
\Delta G_{\mathrm{ads}}^{0}=-R T \ln \left(1 \times 10^{6} \mathrm{~K}_{\mathrm{ads}}\right)
$$

where, $R=$ universal gas constant, $T=$ absolute temperature, and the factor $1 \times 10^{6}$ is $\left[\mathrm{H}_{2} \mathrm{O}\right]$ stated in $\mathrm{g} \mathrm{L}^{-1}$. Anti-corrosive additives are supposed to adsorb at a $\mathrm{C}$-steel/medium interface with a sequences of protuberant binding centers. As all centers are conformable, so each center could connect to only one inhibitor.

The obtained thermodynamic indices from the Langmuir adsorption model for the as-fabricated nanocomposites are recorded in Table 3. It is noticeable from the findings that high $K_{\text {ads }}$ values indicate the powerful interaction between the investigated PAC/nMONPs and metal surfaces. Recently, it was found that high values of $K_{\text {ads }}$ touch on more powerful and steadier adsorbed film development on the C-steel interface [62]. In general, a value of $\Delta G_{\text {ads }}^{0}$ higher than or around $-40.0 \mathrm{~kJ} \mathrm{~mol}^{-1}$ (more negative) comprises charge sharing between the C-steel and nanocomposites (chemical adsorption) [63]. In the present 
work, the computed $\Delta G_{\text {ads }}^{0}$ values for as-prepared nanocomposites PAC, PAC/CuONPs, $\mathrm{PAC} / \mathrm{Fe}_{3} \mathrm{O}_{4} \mathrm{NPs}$ and PAC/NiONPs are $-45.82,-46.26,-46.79$ and $-47.34 \mathrm{~kJ} \mathrm{~g}^{-1}$, respectively. This is a suggestion of predominant chemical adsorption, but the physical adsorption contribution could also be measured owing to the opportunity of development of protonated compound which could interact electrostatically with a charged steel surface.
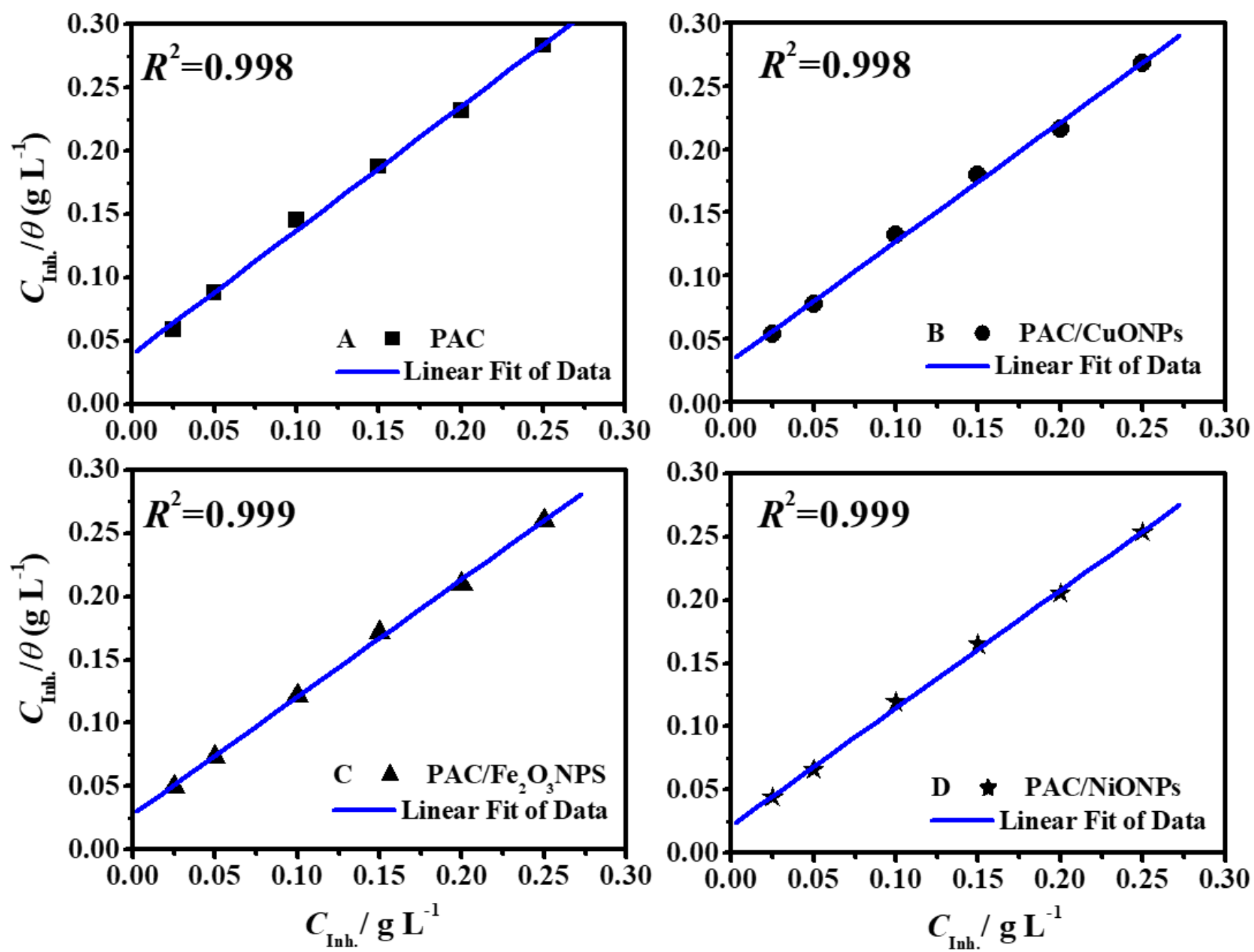

Figure 10. Langmuir profile of $\mathrm{C} / \theta$ vs. $\mathrm{C}$ from potentiodynamic polarization (PDP) findings for $\mathrm{C}$-steel in $1.0 \mathrm{M} \mathrm{HCl}$ solution in the presence of (A) PAC, (B) PAC/CuONPs, (C) PAC $/ \mathrm{Fe}_{3} \mathrm{O}_{4} \mathrm{NPs}$, and (D) PAC/NiONPs at $50{ }^{\circ} \mathrm{C}$.

\subsection{Comparative Study with Some Reported Inhibitors}

We have compared the protection capacity of the as-prepared PAC, PAC/CuONPs, $\mathrm{PAC} / \mathrm{Fe}_{3} \mathrm{O}_{4} \mathrm{NPs}$, and PAC/NiONPs intended from the potentiodynamic polarization studies with the formerly reported additives on the analogous substrate. A comparative investigation of our obtained outcomes with analogous studies $[65,73-75]$ has been recorded in Table 4 . With noteworthy protection for $\mathrm{C}$-steel in acidic pickling solutions $(\mathrm{HCl})$ at a dose as low as $250 \mathrm{mg} \mathrm{L}^{-1}$ for PAC, PAC/CuO, PAC $/ \mathrm{Fe}_{3} \mathrm{O}_{4}$ and PAC $/ \mathrm{NiO}$ nanocomposites could serve as anticorrosive inhibitors for $\mathrm{C}$-steel in an acidic environment as the marketable additives with practical industrial application. 
Table 4. Comparison of the protection capacity of synthesized nanocomposites with existing literature.

\begin{tabular}{|c|c|c|c|c|}
\hline Substrate & Corrosive Media & Inhibitor/Dose & Protection Capacity & References \\
\hline St37 Steel & $15 \% \mathrm{H}_{2} \mathrm{SO}_{4}$ & $\begin{array}{l}1000 \text { ppm carboxymethyl cellulose/ } \\
\text { silver nanoparticles composite }\end{array}$ & 92.12 & Ref. [65] \\
\hline X60 pipeline steel & $\begin{array}{c}3.5 \% \mathrm{NaCl} \text { saturated } \\
\text { with } \mathrm{CO}_{2}\end{array}$ & 100 ppm chitosan & 45 & Ref. [73] \\
\hline X60 pipeline steel & $\begin{array}{c}3.5 \% \mathrm{NaCl} \text { saturated } \\
\text { with } \mathrm{CO}_{2}\end{array}$ & 100 ppm carboxymethyl cellulose & 39 & Ref. [73] \\
\hline X60 pipeline steel & $\begin{array}{c}3.5 \% \mathrm{NaCl} \text { saturated } \\
\text { with } \mathrm{CO}_{2}\end{array}$ & 100 ppm commercial inhibitor & 88 & Ref. [73] \\
\hline Mild steel & $2.0 \mathrm{M} \mathrm{H}_{2} \mathrm{SO}_{4}$ & 500 ppm carboxymethyl cellulose & 66.2 & Ref. [74] \\
\hline Mild steel & $1.0 \mathrm{M} \mathrm{HCl}$ & $\begin{array}{l}700 \text { ppm sodium carboxymethyl } \\
\text { cellulose }\end{array}$ & 86.8 & Ref. [75] \\
\hline C-steel & Molar $\mathrm{HCl}$ & 250 ppm PAC & 88.1 & Present work \\
\hline C-steel & Molar $\mathrm{HCl}$ & 250 ppm PAC/CuONPs & 93.2 & Present work \\
\hline C-steel & Molar $\mathrm{HCl}$ & $250 \mathrm{ppm} \mathrm{PAC} / \mathrm{Fe}_{3} \mathrm{O}_{4} \mathrm{NPs}$ & 96.1 & Present work \\
\hline C-steel & Molar $\mathrm{HCl}$ & 250 ppm PAC/NiONPs & 98.6 & Present work \\
\hline
\end{tabular}

\subsection{Surface Morphology}

\subsubsection{FE-SEM and EDX Analysis}

The surface topology of C-steel owing to the process of corrosion was inspected under FE-SEM micrographs accompanied by EDX to measure the elemental arrangements on the metal interface before and after immersion in the corrosive medium in the lack and the occurrence of as-prepared nanocomposites. Figure 11A-D shows an arrangement of the FE-SEM (I) and EDX (II) analyses for (A) polished C-steel, (B) corroded metal in $\mathrm{HCl}$ free inhibitor, (C) C-steel with the occurrence of $250 \mathrm{ppm} \mathrm{PAC}$, and (D) C-steel with the presence of $250 \mathrm{ppm}$ PAC/NiONPs. No signal of corrosion accomplishment has occurred on the pristine C-steel surface presented in Figure 11A.

Figure 11B exposed that, without any inhibitors (blank medium $1.0 \mathrm{M} \mathrm{HCl}$ ), the C-steel surface looked to be extremely damaged with parts of restricted corrosion. Nevertheless, in the solution containing $250 \mathrm{mg} \mathrm{L}^{-1}$ PAC in Figure 11C, the corrosion action was repressed as observed from the decline in restricted corrosion zones. This is related to the PAC additive adsorption at the metal/solution interface creating a mono-film of protection vs. corrosion action. A smoother C-steel surface could be detected from Figure 11D in the inhibited system containing $250 \mathrm{mg} / \mathrm{L}$ PAC/NiONPs. This elucidates a more reduction in the corrosion activity and might be owing to the co-adsorption of PAC and NiONPs species on the metal surface, consequently advancing inhibition capacity.

From EDX analysis in Figure 11II and Table 5, elemental investigation of the corroded specimen, Figure 11B(II) using EDX indicated that the percentage of $\mathrm{Cl}$ and $\mathrm{O}$ are largely owing to the development of corrosion film from adsorptive ferrous-chloride $(\mathrm{FeCl})_{\text {ads }}$, which could promote corrosion to produce $\mathrm{FeOOH}$ and $\mathrm{Fe}(\mathrm{OH})_{3}$ [76]. In the presence of an aggressive medium containing $250 \mathrm{mg} \mathrm{L}^{-1} \mathrm{PAC}$, only with a quantity of chloride and oxygen was it noticed demonstrating that the corrosion activity had been repressed considerably, in addition to the appearance of a new peak for $\mathrm{N}$ atoms. The occurrence of $\mathrm{PAC}$ as an additive reduced the $\mathrm{O}$ reduction route, therefore, decreasing the rate of corrosion. The declined $\mathrm{O}$ value displays the inhibitor activity [77].

PAC/NiONPs showed a positive effect in prohibiting the C-steel corrosion as displayed in the FE-SEM micrograph (Figure 11D). The Fe\% is more than that of the corroded specimen with only less than $13 \%$ elements of $\mathrm{O}$ and $\mathrm{Cl}$. Additional negative charge produced from the $\mathrm{Cl}^{-}$adsorption enhances interaction by electrostatic with protonated PAC/NiONPs (due to the presence of primary $-\mathrm{NH}_{2}$ ) (cation) [78]. Interaction by electrostatic was supposed to be produced between $\left(\mathrm{FeCl}^{-}\right)$ads species at anodic positions and the 
protonated molecules [79]. Surface morphology using FE-SEM demonstrated a substantial enhancement on the interface of the C-steel substrates in the existence of an optimum dose of 250 ppm of PAC and PAC/NiONPs inhibitors.
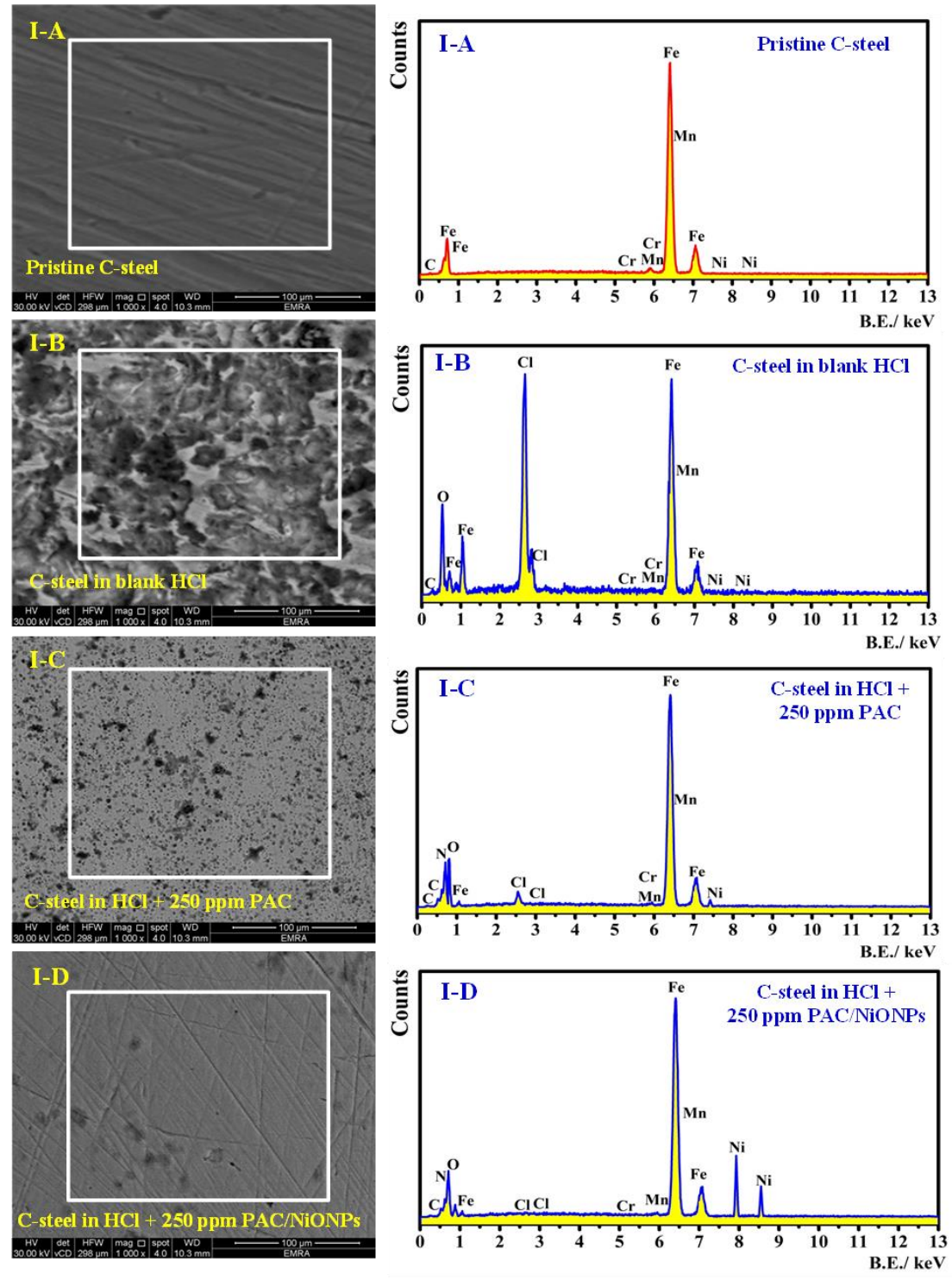

Figure 11. FE-SEM (I) and EDX (II) analyses for (A) pristine C-steel, (B) corroded C-steel in blank $\mathrm{HCl}$, (C) C-steel with the occurrence of $250 \mathrm{ppm}$ PAC and (D) C-steel with the presence of $250 \mathrm{ppm}$ PAC/NiONPs.

Table 5. The element percentage for each sample obtained from the EDX analysis after $48 \mathrm{~h}$ immersion in molar hydrochloric acid.

\begin{tabular}{|c|c|c|c|c|c|c|c|c|}
\hline \multirow{2}{*}{ Specimen } & \multicolumn{8}{|c|}{ Element $(\% \mathrm{wt})$} \\
\hline & Fe & C & $\mathrm{Cr}$ & Mn & $\mathrm{Ni}$ & $\mathbf{O}$ & $\mathbf{N}$ & $\mathrm{Cl}$ \\
\hline (A) Pristine C-steel & 98.94 & 0.19 & 0.75 & 0.06 & 0.06 & - & - & - \\
\hline (B) C-steel in molar $\mathrm{HCl}$ & 61.34 & 0.18 & 0.61 & 0.05 & 0.02 & 16.15 & - & 21.65 \\
\hline (C) C-steel in molar $\mathrm{HCl}+250$ ppm PAC & 86.12 & 4.67 & 0.23 & 0.03 & 0.05 & 4.37 & 2.37 & 2.21 \\
\hline $\begin{array}{l}\text { (D) C-steel in molar } \mathrm{HCl}+250 \mathrm{ppm} \\
\mathrm{PAC} / \mathrm{NiONPs}\end{array}$ & 87.25 & 3.04 & 0.16 & 0.04 & 3.16 & 3.08 & 1.87 & 1.40 \\
\hline
\end{tabular}




\subsubsection{FI-TR Analysis}

Herein, FT-IR examinations were used to confirm that the corrosion inhibition of C-steel in the investigated corrosive medium is associated with the inhibitor adsorption on the metallic interface. In FT-IR exploration of PAC/NiONPs inhibitor (line A), the adsorbed film formed on the $\mathrm{C}$-steel surface after dipping in molar $\mathrm{HCl}$ containing $250 \mathrm{ppm}$ PAC/NiONPs (line B) is presented in Figure 12. PAC/NiONPs compound has diverse effective groups that possess an electron cloud. This designates that the adsorption layer between the prepared PAC/NiONPs inhibitor and empty d-orbitals of Fe is probable to occur within these well-designed groups. The FT-IR feature of PAC/NiONPs and the film formed on the electrode interface via adsorption were reasonably clarified. The broad peak (peak 1) at near $3340 \mathrm{~cm}^{-1}$ is related to the $-\mathrm{OH}$ in PAC/NiONPs. This broadband (peak 1; Figure 12B) disappeared in the case of an inhibited system (adsorbed layer), which could be ascribed to the chemical bond formed at the C-steel surface (Figure 12B). Furthermore, bands 2 and 3 (Figure 12A) at $1669 \mathrm{~cm}^{-1}$ and $1332 \mathrm{~cm}^{-1}$ related to the -C-N- peak, the frequency absorption bands altered to $1639 \mathrm{~cm}^{-1}$ and $1484 \mathrm{~cm}^{-1}$ with PAC/NiONPs (Figure 12B). The modifications in absorption bands display the adsorption of diverse functional groups of the PAC/NiONPs at the interface of the metal/electrolyte and the formation of [Fe PAC/NiONPs] on the metallic interface [80]. Mourya et al. specified that the variation in peaks is either because of adsorption, or due to optical effects, or owing to chemical reactions with the electrolyte.

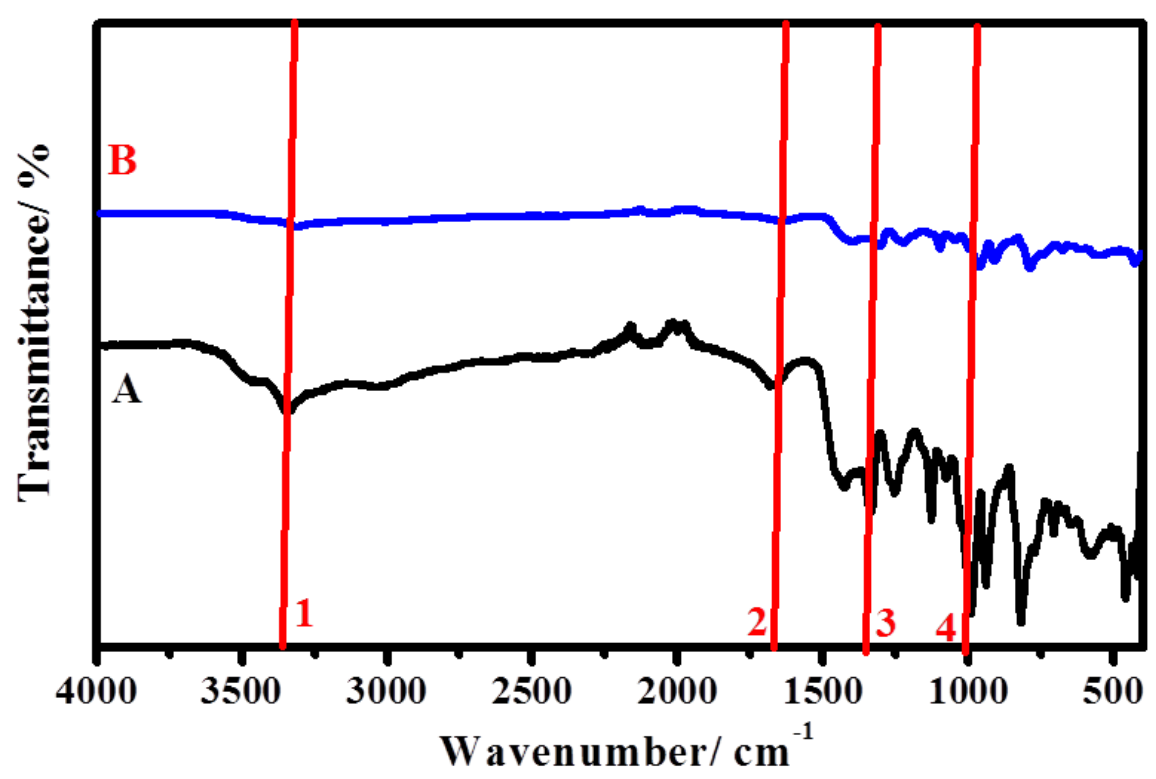

Figure 12. FT-IR spectra of (A) crude PAC/NiONPs inhibitor, (B) adsorbed film formed on the C-steel surface after dipping in $1.0 \mathrm{M} \mathrm{HCl}$ containing $250 \mathrm{ppm}$ PAC/NiONPs.

\subsection{The Corrosion Mitigation Mechanism by Primary Aminated Modified Cellulose (PAC) Containing Nano-Oxide of Some Metals (MONPS)}

From the attained data in this study, individual PAC has reasonable protection efficacy on C-steel in molar $\mathrm{HCl}$ medium. From Table 1, the highest protection capacity in the existence of $250 \mathrm{ppm}$ PAC is $88.1 \%$ at $50{ }^{\circ} \mathrm{C}$ from PDP experiments. The value of $\Delta G_{\text {ads }}^{0}$ displayed that the PAC adsorption at the metal/electrolyte interface involves predominant chemical adsorption, but the physical adsorption also contributed. In the studied acidic solution, $\mathrm{PAC}$ polymer was primarily present in $\mathrm{PACH}^{+}$(protonated structure), and when the $\mathrm{C}$-steel surface attained positive charge, consequently, the metal surface was hydrated with $\mathrm{Cl}^{-}$ions, and the PAC protonated compound could interact electrostatically with a negatively charged steel surface (physical adsorption). 
As well as the physical adsorption, there should be chemisorption attributed to the coordinate bonds that might be designed among vacant d-orbitals of Fe surface and efficient groups in PAC molecules. The achieved outcomes in the present study display that the protection efficacy and stability of PAC have been significantly improved by the incorporation of $\mathrm{Fe}_{3} \mathrm{O}_{4}, \mathrm{CuO}$, and $\mathrm{NiO}$ NPs in the PAC matrix. For instance, $250 \mathrm{ppm} \mathrm{PAC} / \mathrm{Fe}_{3} \mathrm{O}_{4} \mathrm{NPs}$, $\mathrm{PAC} / \mathrm{CuONPs}$, and PAC/NiONPs in molar $\mathrm{HCl}$ medium at $50{ }^{\circ} \mathrm{C}$ reveal inhibition efficiency of $93.2,96.1$ and $98.6 \%$, respectively. Remarkably, when the metal electrode was dipped in $\mathrm{HCl}$ containing $\mathrm{PAC} / \mathrm{Fe}_{3} \mathrm{O}_{4} \mathrm{NPs}$, PAC/CuONPs, and PAC/NiONPs nanocomposites, the cationic form of additive species first adsorbed at the electrode/electrolyte surface via physical adsorption between the protonated $\mathrm{PAC} / \mathrm{Fe}_{3} \mathrm{O}_{4} \mathrm{NPs}, \mathrm{PAC} / \mathrm{CuONPs}$, and $\mathrm{PAC} / \mathrm{NiONPs}$ molecules and the $\mathrm{Cl}^{-}$ions hydrated interface. It appears that attractions occur among the iron-atoms on the steel metal and $\mathrm{Fe}_{3} \mathrm{O}_{4}, \mathrm{CuO}$, and $\mathrm{NiO} \mathrm{NPs}$ as a result of the efficient characteristics of the $\mathrm{Fe}_{3} \mathrm{O}_{4}, \mathrm{CuO}$, and NiO NPs [64]. The hetero-atoms in PAC have a lone pair of electrons that could be transferred to the vacant d-orbital of Fe. The existence of MONPs $\left(\mathrm{Fe}_{3} \mathrm{O}_{4} \mathrm{NPs}, \mathrm{CuONPs}\right.$ and NiONPs) in the PAC construction may have also prohibited the polymer torsion [65], which leads to total coverage of the metal interface.

\section{Conclusions}

In this study, primary aminated cellulose (PAC) and the in-situ deposition of some metal oxide nanoparticles (MONPs) in PAC matrix were prepared, and their structures were characterized through FT-IR, FE-SEM/EDX, TEM, SAED, and XRD. For the first time, PAC, PAC $/ \mathrm{Fe}_{3} \mathrm{O}_{4} \mathrm{NPs}$, PAC/CuONPs, and PAC/NiONPs exhibited superior inhibitive action for $\mathrm{C}$-steel in acidic chloride solutions. The protection capacities of these as-prepared nanocomposites by electrochemical approaches and weight-loss experiments followed the order of PAC/NiONPs $(98.6 \%)>$ PAC $/ \mathrm{Fe}_{3} \mathrm{O}_{4} \mathrm{NPs}(96.1 \%)>\mathrm{PAC} / \mathrm{CuONPs}(93.2 \%)>$ PAC $(88.1 \%)$. The PDP profiles demonstrated that the synthesized nanocomposites act as the inhibitors of mixed-type, whereas the intended thermodynamic parameters specified chemisorption as the main adsorption that follows the Langmuir isotherm model. The surface topology was evaluated by FT-IR, FE-SEM, and EDX analysis, and established the adsorption of PAC, $\mathrm{PAC} / \mathrm{Fe}_{3} \mathrm{O}_{4} \mathrm{NPs}, \mathrm{PAC} / \mathrm{CuONPs}$, and PAC/NiONPs molecules at the metal $/ \mathrm{HCl}$ interface and that they accordingly played a role in the worthy corrosion protection activity. Therefore, it could be decided that PAC and PAC/MONPs are respectable eco-friendly inhibitors for steel corrosion in pickling $\mathrm{HCl}$ solutions.

Author Contributions: Conceptualization, H.M.A.E.-L. and M.G.; supervision, H.M.A.E.-L. and M.G.; investigation, H.M.A.E.-L. and M.G.; methodology, H.M.A.E.-L. and M.G.; resources, H.M.A.E.-L. and M.G.; formal analysis, H.M.A.E.-L. and M.G.; data curation, H.M.A.E.-L. and M.G.; funding acquisition, H.M.A.E.-L. and M.G.; writing—original draft, H.M.A.E.-L. and M.G.; writing—review and editing. H.M.A.E.-L. and M.G. All authors have read and agreed to the published version of the manuscript.

Funding: This research was funded by deanship of Scientific Research, King Faisal University, Saudi Arabia (Grant No. 206170).

Institutional Review Board Statement: Not applicable.

Informed Consent Statement: Not applicable.

Data Availability Statement: The raw/processed data generated in this work are available upon request from the corresponding author.

Acknowledgments: The authors acknowledge the Deanship of Scientific Research at King Faisal University, Saudi Arabia for the financial support under Nasher Track (Grant No. 206170).

Conflicts of Interest: The authors declare that they have no known competing financial interest or personal relationships that could have appeared to influence the work reported in this paper. 


\section{References}

1. Finšgar, M.; Jackson, J. Application of corrosion inhibitors for steels in acidic media for the oil and gas industry: A review. Corros. Sci. 2014, 86, 17-41. [CrossRef]

2. Jadhav, R.S.; Hundiwale, D.G.; Mahulikar, P.P. Synthesis of nano polyaniline and poly-o-anisidine and applications in alkyd paint formulation to enhance the corrosion resistivity of mild steel. J. Coat. Technol. Res. 2010, 7, 449-454. [CrossRef]

3. Sayed, R.A.; Abd El-lateef, H.M.; Mohamad, A.D.M. Polyhydrazide Incorporated with Thiadiazole Moiety as Novel and Effective Corrosion Inhibitor for C-Steel in Pickling Solutions of $\mathrm{HCl}$ and $\mathrm{H}_{2} \mathrm{SO}_{4}$. Macromol. Res. 2018, 26, 882-891. [CrossRef]

4. Abd El-lateef, H.M.; Albokheet, W.A.; Gouda, M. Carboxymethyl cellulose/metal (Fe, $\mathrm{Cu}$ and Ni) nanocomposites as nonprecious inhibitors of $\mathrm{C}$-steel corrosion in $\mathrm{HCl}$ solutions: Synthesis, characterization, electrochemical and surface morphology studies. Cellulose 2020, 27, 8039-8057. [CrossRef]

5. Umoren, S.A.; Ogbobe, O.; Igwe, I.O.; Ebenso, E.E. Inhibition of mild steel corrosion in acidic medium using synthetic and naturally occurring polymers and synergistic halide additives. Corros. Sci. 2008, 50, 1998-2006. [CrossRef]

6. Abd El-lateef, H.M.; Alnajjar, A.O. Enhanced the protection capacity of poly(o-toluidine) by synergism with zinc or lanthanum additives at C-steel/ $\mathrm{HCl}$ interface: A combined DFT, molecular dynamic simulations and experimental methods. J. Mol. Liq. 2020, 303, 112641. [CrossRef]

7. Bayol, E.; Gürten, A.A.; Dursun, M.; Kayakirilmaz, K. Adsorption behavior and inhibition corrosion effect of sodium carboxymethyl cellulose on mild steel in acidic medium. Acta Phys.-Chim. Sin. 2008, 24, 2236-2243. [CrossRef]

8. Abd EL-lateef, H.M.; Elrouby, M. Synergistic inhibition effect of poly(ethylene glycol) and cetyltrimethylammonium bromide on corrosion of $\mathrm{Zn}$ and $\mathrm{Zn}-\mathrm{Ni}$ alloys for alkaline batterie. Trans. Nonferrous Met. Soc. China 2020, 30, 259-274. [CrossRef]

9. Umoren, S.A.; Solomon, M.M.; Udosoro, I.I.; Udoh, A.P. Synergistic and antagonistic effects between halide ions and carboxymethyl cellulose for the corrosion inhibition of mild steel in sulphuric acid solution. Cellulose 2010, 17, 635-648. [CrossRef]

10. Al-Shihry, S.S.; Sayed, A.R.; Abd El-lateef, H.M. Design and assessment of a novel poly (urethane-semicarbazides) containing thiadiazoles on the backbone of the polymers as inhibitors for steel pipelines corrosion in $\mathrm{CO}_{2}$-saturated oilfield water. J. Mol. Struct. 2020, 1201, 127223. [CrossRef]

11. Rahim, A.A.; Rocca, E.; Steinmetz, E.J. Inhibitive action of mangrove tannins and phosporic acid on pre-rusted steel via electrochemical methods. Corros. Sci. 2008, 50, 1546-1550. [CrossRef]

12. Raja, P.B.; Fadaeinasab, M.; Quresi, A.K. Evaluation of green corrosion inhibition by alkaloid extracts of Ochrosia oppositifolia and Isoreserpiline against mild steel in $1 \mathrm{M} \mathrm{HCl}$ medium. Ind. Eng. Chem. Res. 2013, 52, 10582-10593. [CrossRef]

13. Rajendran, S.; Sridevi, S.P.; Anthony, N.; Amalraj, A.J.; Sundaravadivelu, M. Corrosion behaviour of carbon steel in polyvinyl alcohol. Anti-Corros. Methods Mater. 2005, 52, 102-107. [CrossRef]

14. Abd El-Lateef, H.M.; Shalabi, K.; Sayed, A.R.; Gomha, S.M.; Bakir, E.M. The novel polythiadiazole polymer and its composite witha- $\mathrm{Al}(\mathrm{OH})_{3}$ as inhibitors for steel alloy corrosion in molar $\mathrm{H}_{2} \mathrm{SO}_{4}$ : Experimental and computational evaluations. J. Ind. Engin. Chem. 2022, 105, 238-250. [CrossRef]

15. Shukla, R.K.; Tiwari, A. Carbohydrate polymers: Applications and recent advances in delivering drugs to the colon. Carbohydr. Polym. 2012, 88, 399-416. [CrossRef]

16. Dai, H.; Huang, Y.; Huang, H. Eco-friendly polyvinyl alcohol/carboxymethyl cellulose hydrogels reinforced with graphene oxide and bentonite for enhanced adsorption of methylene blue. Carbohydr. Polym. 2018, 185, 1-11. [CrossRef]

17. Mu, J.; Zhou, H.; Chen, Y. Revealing a novel bioflocculants resource from Ruditapes philllippinarum: Effective polysaccharides and synergistic flocculation. Carbohydr. Polym. 2018, 16, 17-24. [CrossRef]

18. Unuabonah, E.I.; Adewuyi, A.; Kolawole, M.O. Disinfection of water with new chitosan-modified hybrid clay composites adsorbents. Heliyon 2017, 3, e00379. [CrossRef]

19. Fattah, M.A.; Hasan, A.M.A.; Keshawy, M. Nanocrystalline cellulose as an eco-friendly reinforcing additive to polyurethane coating for augmented anticorrosive behavior. Carbohydr. Polym. 2018, 183, 311-318. [CrossRef]

20. Sadjadi, S.; Heravi, M.M.; Malmir, M. Pd@HNTs-CDNS-g-C3N4: A novel heterogeneous catalyst for promoting ligand and copperfree Sonogashira and Heck coupling reactions, benefits from halloysite and cyclodextrin chemistry and g-C3N4 contribution to suppress Pd leaching. Carbohydr. Polym. 2018, 186, 25-34. [CrossRef]

21. Pettignano, A.; Charlot, A.; Fleury, E. Solvent-Free Synthesis of Amidated Carboxymethyl Cellulose Derivatives: Effect on the Thermal Properties. Polymers 2019, 11, 1227. [CrossRef] [PubMed]

22. Shi, S.C. Electrochemical Properties of Biopolymers in Strong Acid and Application in Displacement Sensor. Sens. Mater. 2019, 31, 1599-1608. [CrossRef]

23. Deng, S.; Li, X.; Xie, X. Hydroxymethyl urea and 1,3-bis(hydroxymethyl) urea as corrosion inhibitors for steel in $\mathrm{HCl}$ solution. Corros. Sci. 2014, 80, 276-289. [CrossRef]

24. Ashassi-Sorkhabi, H.; Kazempou, A. Chitosan, its derivatives and composites with superior potentials for the corrosion protection of steel alloys: A comprehensive review. Carbohydr. Polym. 2020, 237, 116110. [CrossRef] [PubMed]

25. El-Haddad, M.N. Chitosan as a green inhibitor for copper corrosion in acidic medium. Int. J. Biol. Macromol. 2013, 55, 142-149. [CrossRef]

26. Waanders, F.B.; Vorster, S.W.; Geldenhuys, A.J. Biopolymer corrosion inhibition of mild steel: Electrochemical/mössbauer results. Hyperfine Interact. 2002, 139, 133-139. [CrossRef] 
27. Fekry, A.M.; Mohamed, R.R. Acetyl thiourea chitosan as an eco-friendly inhibitor for mild steel in sulphuric acid medium. Electrochim. Acta 2010, 55, 1933-1939. [CrossRef]

28. Cheng, S.; Chen, S.; Liu, T.; Chang, X.; Yin, Y. Carboxymenthylchitosan as an ecofriendly inhibitor for mild steel in $1 \mathrm{M}$ HCl. Mater. Lett. 2007, 61, 3276-3280. [CrossRef]

29. Baoa, Q.; Zhanga, D.; Wan, Y. 2-Mercaptobenzothiazole doped chitosan/11- alkanethiolate acid composite coating: Dual function for copper protection. Appl. Surf. Sci. 2011, 257, 10529-10534. [CrossRef]

30. Sathiyanarayanan, S.; Balakrishnan, K.; Dhawan, S.K.; Trivedi, D.C. Prevention of corrosion of iron in acidic media using poly (o-methoxy-aniline). Electrochim. Acta 1994, 39, 831-837. [CrossRef]

31. El-Sayed, A. A study of the inhibiting action of some polymers on the corrosion of iron in acidic media. Corros. Prev. Control 1996, $43,27-34$.

32. Ashassi-Sorkhabi, H.; Ghalebsaz-Jeddi, N. Inhibition effect of polyethylene glycol on the corrosion of carbon steel in sulphuric acid. Mater. Chem. Phys. 2005, 92, 480-486. [CrossRef]

33. WHO Food Additives and Contaminants; Food Additives series 40; WHO: Genev, Switzerland, 1998.

34. Arukalam, I.O. The inhibitive effect of hydroxyethylcellulose on mild steel corrosion in hydrochloric acid solution. Acad. Res. Int. 2012, 2, 35-42.

35. Farguez, P.; Avilés, F.; Oliva, A.I. Mechanical properties of gold nanometric films onto a polymeric substrate. Surf. Coat. Technol. 2008, 202, 1556-1563. [CrossRef]

36. Sabzi, M.; Mirabedini, S.M.; Zohuriaan-Mehr, J.; Atai, M. Surface modification of $\mathrm{TiO}_{2}$ nano-particles with silane coupling agent and investigation of its effect on the properties of polyurethane composite coating. Prog. Org. Coat. 2009, 65, 222-228. [CrossRef]

37. Yiu-Wing, M.; Zhong-Zhen, Y. Polymer Nanocomposites; Wood head Publishing Limited: Cambridge, UK, 2006.

38. Zubillaga, O.; Cano, F.J.; Azkarate, I.; Molchan, I.S.; Thompson, G.E.; Skeldon, P. Anodic films containing polyaniline and nanoparticles for corrosion protection of AA2024T3 aluminium alloy. Surf. Coat. Technol. 2009, 203, 1494-1501. [CrossRef]

39. Gao, G.; Wu, H.; He, R.; Cui, D. Corrosion inhibition during synthesis of $\mathrm{Cu}_{2} \mathrm{O}$ nanoparticles by 1,3-diaminopropylene in solution. Corros. Sci. 2010, 52, 2804-2812. [CrossRef]

40. Zhang, X.; Wang, F.; Du, Y. Effect of nano-sized titanium powder addition on corrosion performance of epoxy coatings. Surf. Coat. Technol. 2007, 201, 7241-7245. [CrossRef]

41. Behzadnasab, M.; Mirabedini, S.M.; Kabiri, K.; Jamali, S. Corrosion performance of epoxy coatings containing silane treated $\mathrm{ZrO}_{2}$ nanoparticles on mild steel in 3.5\% NaCl solution. Corros. Sci. 2011, 53, 89-98. [CrossRef]

42. Atta, A.M.; El-Azabawy, O.E.; Ismail, H.S.; Hegazy, M.A. Novel dispersed magnetite core-shell nanogel polymers as corrosion inhibitors for carbon steel in acidic medium. Corros. Sci. 2011, 53, 1680-1689. [CrossRef]

43. Li, Y.; Fedkiw, P.S. Effect of gel electrolytes containing silica nanoparticles on aluminum corrosion. Electrochim. Acta 2007, 52, 2471-2477. [CrossRef]

44. Truc, T.A.; Hang, T.T.X.; Oanh, V.K.; Dantras, E.; Lacabanne, C.; Oquab, D.; Pébère, N. Incorporation of an indole-3 butyric acid modified clay in epoxy resin for corrosion protection of carbon steel. Surf. Coat. Technol. 2008, 202, 4945-4951. [CrossRef]

45. Quadri, T.W.; Lukman, O.O.; Omolola, E.F.; Moses, M.S.; Eno, E.E. Zinc Oxide Nanocomposites of Selected Polymers: Synthesis, Characterization, and Corrosion Inhibition Studies on Mild Steel in HCl Solution. ACS Omega 2017, 2, 8421-8437. [CrossRef]

46. Ross, J.H.; Baker, D.; Coscia, A.T. Some reactions of epichlorohydrin with amines. J. Org. Chem. 1964, 29, 824-826. [CrossRef]

47. Khalil, M.; Farag, S. Preparation of some cationic starches using the dry process. Starch-Stärke 1998, 50, 267-271. [CrossRef]

48. Gouda, M.; Aljaafari, A.; Al-Fayz, Y.; Boraie, W. Preparation and characterization of some nanometal oxides using microwave technique and their application to cotton fabrics. J. Nanomater. 2015, 2015, 586904. [CrossRef]

49. Hospodarova, V.; Singovszka, E.; Stevulova, N. Characterization of cellulosic fibers by FTIR spectroscopy for their further implementation to building materials. Am. J. Anal. Chem. 2018, 9, 303-310. [CrossRef]

50. Jóźwiak, T.; Filipkowska, U.; Brym, S.; Zyśk, M. The use of aminated cotton fibers as an unconventional sorbent to remove anionic dyes from aqueous solutions. Cellulose 2020, 27, 3957-3969. [CrossRef]

51. Sheena, P.; Priyanka, K.; Sabu, B. Varghese Effect of calcination temperature on the structural and optical properties of nickel oxide nanoparticles. Nanosyst. Phys. Chem. Math. 2014, 5, 441-449.

52. Xu, J.; Li, S.; Tan, L.; Kou, B. Enhanced catalytic activity of mesoporous graphitic carbon nitride on thermal decomposition of ammonium perchlorate via copper oxide modification. Mater. Res. Bull. 2017, 93, 352-360. [CrossRef]

53. Ta, T.K.H.; Trinh, M.-T.; Long, N.V.; Nguyen, T.T.M.; Nguyen, T.L.T.; Thuoc, T.L.; Phan, B.T.; Mott, D.; Maenosono, S.; Tran-Van, H. Synthesis and surface functionalization of $\mathrm{Fe}_{3} \mathrm{O}_{4}-\mathrm{SiO}_{2}$ core-shell nanoparticles with 3-glycidoxypropyltrimethoxysilane and 1, 1'-carbonyldiimidazole for bio-applications. Colloids Surf. A Physicochem. Eng. Asp. 2016, 504, 376-383. [CrossRef]

54. Diva, T.N.; Zare, K.; Taleshi, F.; Yousefi, M. Synthesis, characterization, and application of nickel oxide/CNT nanocomposites to remove $\mathrm{Pb}^{2+}$ from aqueous solution. J. Nanostruct. Chem. 2017, 7, 273-281. [CrossRef]

55. Ishak, W.H.W.; Ahmad, I.; Ramli, S.; Amin, M.C.I.M. Gamma irradiation-assisted synthesis of cellulose nanocrystal-reinforced gelatin hydrogels. Nanomaterials 2018, 8, 749. [CrossRef]

56. Srivastava, N.; Srivastava, P. Realizing NiO nanocrystals from a simple chemical method. Bull. Mater. Sci. 2010, 33, 653-656. [CrossRef]

57. Batool, M.; Qureshi, M.Z.; Hashmi, F.; Mehboob, N.; Shah, A.S. Congo Red Azo Dye Removal and Study of Its Kinetics by Aloe Vera Mediated Copper Oxide Nanoparticles. Indones. J. Chem. 2019, 19, 626-637. [CrossRef] 
58. Kumar, P.; Nene, A.G.; Punia, S.; Kumar, M.; Abbas, Z.; Thakral, F.; Tuli, H.S. Synthesis, Characterization and antibacterial activity of $\mathrm{CuO}$ nanoparticles. Int. J. Appl. Pharm. 2020, 12, 17-20. [CrossRef]

59. Noval, V.E.; Carriazo, J.G. $\mathrm{Fe}_{3} \mathrm{O}_{4}-\mathrm{TiO}_{2}$ and $\mathrm{Fe}_{3} \mathrm{O}_{4}-\mathrm{SiO}_{2}$ core-shell powders synthesized from industrially processed magnetite $\left(\mathrm{Fe}_{3} \mathrm{O}_{4}\right)$ microparticles. Mater. Res. 2019, 22, e20180660. [CrossRef]

60. Wang, C.; Chen, J.; Hu, B.; Liu, Z.; Wang, C.; Han, J.; Su, M.; Li, Y.; Li, C. Modified chitosan-oligosaccharide and sodium silicate as efficient sustainable inhibitor for carbon steel against chloride-induced corrosion. J. Clean. Prod. 2019, 238, 117823. [CrossRef]

61. Abdeen, D.H.; El Hachach, M.; Koc, M.; Atieh, M.A. A Review on the Corrosion Behaviour of Nanocoatings on Metallic Substrates. Materials 2019, 12, 210. [CrossRef]

62. Abd El-Lateef, H.M.; Mohamed, I.M.A.; Zhu, J.-H.; Khalaf, M.M. An efficient synthesis of electrospun TiÖ-nanofibers/Schiff base phenylalanine composite and its inhibition behavior for C-steel corrosion in acidic chloride environments. J. Taiwan Inst. Chem. Eng. 2020, 112, 306-321. [CrossRef]

63. Saleh, M.M.; Mahmoud, M.G.; Abd El-lateef, H.M. Comparative study of synergistic inhibition of mild steel and pure iron by 1hexadecylpyridinium chloride and bromide ions. Corros. Sci. 2019, 154, 70-79. [CrossRef]

64. Hefni, H.H.; Azzam, E.M.; Badr, E.A.; Hussein, M.; Tawfik, S.M. Synthesis, characterization and anticorrosion potentials of chitosan-g-PEG assembled on silver nanoparticles. Int. J. Biol. Macromol. 2016, 83, 297-305. [CrossRef] [PubMed]

65. Solomon, M.M.; Gerengi, H.; Umoren, S.A. Carboxymethyl cellulose/silver nanoparticles composite: Synthesis, characterization and application as a benign corrosion inhibitor for $\mathrm{St} 37$ steel in $15 \% \mathrm{H}_{2} \mathrm{SO}_{4}$ medium. ACS Appl. Mater. Interfaces 2017, 9, 6376-6389. [CrossRef]

66. Alam, R.; Mobin, M.; Aslam, J. Investigation of anti-corrosive properties of poly(aniline-co-2-pyridylamine-co-2,3-xylidine) and its nanocomposite poly(aniline-co-2-pyridylamine-co-2,3-xylidine)/ZnO on mild steel in $0.1 \mathrm{M} \mathrm{HCl}$. Appl. Surf. Sci. 2016, 368, 360-367. [CrossRef]

67. Singh, A.; Ansari, K.R.; Haque, J.; Dohare, P.; Lgaz, H.; Salghi, R.; Quraishi, M.A. Effect of electron donating functional groups on corrosion inhibition of mild steel in hydrochloric acid: Experimental and quantum chemical study. J. Taiwan Inst. Chem. Eng. 2018, 82, 233-251. [CrossRef]

68. Ansari, K.R.; Quraishi, M.A. Experimental and computational studies of naphthyridine derivatives as corrosion inhibitor for N80 steel in 15\% hydrochloric acid. Phys. E 2015, 69, 322-331. [CrossRef]

69. Ansari, K.R.; Quraishi, M.A.; Singh, A.; Ramkumar, S.; Obot, I.B. Corrosion inhibition of N80 steel in $15 \% \mathrm{HCl}$ by pyrazolone derivatives: Electrochemical, surface and quantum chemical studies. RSC Adv. 2016, 6, 24130-24141. [CrossRef]

70. Li, X.H.; Deng, S.D.; Fu, H.; Mu, G.N. Inhibition by tween-85 of the corrosion of cold rolled steel in $1.0 \mathrm{M}$ hydrochloric acid solution. J. Appl. Electrochem. 2009, 39, 1125-1135. [CrossRef]

71. Singh, A.; Ansari, K.R.; Quraishi, M.A.; Lgaz, H.; Lin, Y. Synthesis and investigation of pyran derivatives as acidizing corrosion inhibitors for N80 steel in hydrochloric acid: Theoretical and experimental approaches. J. Alloys Compd. 2018, 762, 347-362. [CrossRef]

72. Ansari, K.R.; Quraishi, M.A.; Singh, A. Schiff's base of pyridyl substituted triazoles as new and effective corrosion inhibitors for mild steel in hydrochloric acid solution. Corros. Sci. 2014, 79, 5-15. [CrossRef]

73. Umoren, S.A.; AlAhmary, A.A.; Gasem, Z.M.; Solomon, M.M. Evaluation of Chitosan and Carboxymethyl cellulose as Ecofriendly Corrosion Inhibitors for Steel. Int. J. Biol. Macromol. 2018, 117, 1017-1028. [CrossRef]

74. Solomon, M.M.; Umoren, S.A.; Udosoro, I.I.; Udoh, A.P. Inhibitive and adsorption behaviour of carboxymethyl cellulose on mild steel corrosion in sulphuric acid solution. Corros. Sci. 2010, 52, 1317-1325. [CrossRef]

75. Aslam, R.; Mobin, M.; Aslam, J.; Lgaz, H.; Chung, I.-M. Inhibitory effect of sodium carboxymethylcellulose and synergistic biodegradable gemini surfactants as effective inhibitors for MS corrosion in $1 \mathrm{M} \mathrm{HCl}$. J. Mater. Res. Technol. 2019, 8, 4521-4533. [CrossRef]

76. Marzorati, S.; Verotta, L.; Trasatti, P.S. Green Corrosion Inhibitors from Natural Sources and Biomass Wastes. Molecules 2019, 24, 48. [CrossRef]

77. Odewunmi, N.A.; Umoren, S.A.; Gasem, Z.M.; Ganiyu, S.A.; Muhammad, Q. L-citrulline: An active corrosion inhibitor component of watermelon rind extract for mild steel in $\mathrm{HCl}$ medium. J. Taiwan Inst. Chem. Eng. 2015, 51, 177-185. [CrossRef]

78. Sanaei, Z.; Ramezanzadeh, M.; Bahlakeh, G.; Ramezanzadeh, B. Use of Rosa canina fruit extract as a green corrosion inhibitor for mild steel in $1 \mathrm{M} \mathrm{HCl}$ solution: A complementary experimental, molecular dynamics and quantum mechanics investigation. $J$. Ind. Eng. Chem. 2019, 69, 18-31. [CrossRef]

79. Luo, X.; Ci, C.; Li, J.; Lin, K.; Du, S.; Zhang, H. 4-aminoazobenzene modified natural glucomannan as a green eco-friendly inhibitor for the mild steel in $0.5 \mathrm{M} \mathrm{HCl}$ solution. Corros. Sci. 2019, 151, 132-142. [CrossRef]

80. Mourya, P.; Banerjee, S.; Singh, M.M. Corrosion inhibition of mild steel in acidic solution by Tagetes erecta (Marigold flower) extract as a green inhibitor. Corros. Sci. 2014, 85, 352-361. [CrossRef] 